\title{
Mechanical Effects of Cellulose, Xyloglucan, and Pectins on Stomatal Guard Cells of Arabidopsis thaliana
}

\author{
Hojae Yi ${ }^{1 *}$, Yue Rui ${ }^{2,3 \dagger}$, Baris Kandemir ${ }^{4}$, James Z. Wang ${ }^{4}$, Charles T. Anderson ${ }^{2,3 *}$ and \\ Virendra M. Puri ${ }^{1}$ \\ 1 Department of Agricultural and Biological Engineering, The Pennsylvania State University, University Park, PA, United States, \\ ${ }^{2}$ Department of Biology, The Pennsylvania State University, University Park, PA, United States, ${ }^{3}$ Intercollege Graduate \\ Degree Program in Plant Biology, The Pennsylvania State University, University Park, PA, United States, ${ }^{4}$ College of \\ Information Sciences and Technology, The Pennsylvania State University, University Park, PA, United States
}

OPEN ACCESS

Edited by:

Kim Johnson,

La Trobe University, Australia

Reviewed by:

Benny Bar-On,

Ben-Gurion University of the Negev,

Israel

Mauricio Rincon,

Basque Center for Applied

Mathematics, Spain

*Correspondence:

Hojae $Y_{i}$

huy1@psu.edu

Charles T. Anderson cta3@psu.edu

${ }^{\dagger}$ Present Address:

Yue Rui,

Department of Biology, Stanford University, Stanford, CA, United States

Specialty section:

This article was submitted to Plant Biophysics and Modeling,

a section of the journal

Frontiers in Plant Science

Received: 04 June 2018

Accepted: 08 October 2018

Published: 05 November 2018

Citation:

Yi H, Rui Y, Kandemir B, Wang JZ, Anderson CT and Puri VM (2018)

Mechanical Effects of Cellulose,

Xyloglucan, and Pectins on Stomatal

Guard Cells of Arabidopsis thaliana.

Front. Plant Sci. 9:1566.

doi: 10.3389/fp/s.2018.01566
Stomata function as osmotically tunable pores that facilitate gas exchange at the surface of plants. Stomatal opening and closure are regulated by turgor changes in guard cells that result in mechanically regulated deformations of guard cell walls. However, how the molecular, architectural, and mechanical heterogeneities that exist in guard cell walls affect stomatal dynamics is unclear. In this work, stomata of wild type Arabidopsis thaliana plants or of mutants lacking normal cellulose, hemicellulose, or pectins were experimentally induced to close or open. Three-dimensional images of these stomatal complexes were collected using confocal microscopy, images were landmarked, and three-dimensional finite element models (FEMs) were constructed for each complex. Stomatal opening was simulated with a $5 \mathrm{MPa}$ turgor increase. By comparing experimentally measured and computationally modeled changes in stomatal geometry across genotypes, anisotropic mechanical properties of guard cell walls were determined and mapped to cell wall components. Deficiencies in cellulose or hemicellulose were both predicted to stiffen guard cell walls, but differentially affected stomatal pore area and the degree of stomatal opening. Additionally, reducing pectin molecular mass altered the anisotropy of calculated shear moduli in guard cell walls and enhanced stomatal opening. Based on the unique architecture of guard cell walls and our modeled changes in their mechanical properties in cell wall mutants, we discuss how each polysaccharide class contributes to wall architecture and mechanics in guard cells. This study provides new insights into how the walls of guard cells are constructed to meet the mechanical requirements of stomatal dynamics.

Keywords: stomatal guard cell, plant cell wall, stomatal mechanics, finite element modeling, confocal microscopy, image analysis

\section{INTRODUCTION}

Stomata function as osmotically tunable pores that control $\mathrm{CO}_{2}$ intake and water loss at the surface of plants. Each stomatal pore is surrounded by a pair of specialized guard cells, which gain turgor to pressurize and open the pore, and lose turgor to depressurize and close the pore (Meidner and Mansfield, 1968; Aylor et al., 1973; Zeiger et al., 1987; Niklas, 1992; Franks et al., 1998; Franks and Farquhar, 2001, 2007). For plants to efficiently control photosynthesis and transpiration by 
stomatal opening and closure, stomatal guard cells must repeatedly expand and contract. Thus, the reversible deformations of guard cells make them an intriguing model to study the elastic mechanics of complex biomaterials, complementing studies of cell walls that undergo structural and compositional changes during inelastic growth in other plant cell types (Cosgrove, 2005).

Stomatal opening is thought to be driven by the anisotropic deformation of the guard cell, and such anisotropy is hypothesized to be linked to the molecular construction and mechanical properties of the guard cell wall (Meckel et al., 2007; Amsbury et al., 2016; Rui and Anderson, 2016; Carter et al., 2017; Marom et al., 2017; Woolfenden et al., 2017). For example, cellulose microfibrils (CMFs) have high stiffness, presumably preventing circumferential expansion and favoring cell elongation during stomatal opening (Meckel et al., 2007). Stomata in cellulose-deficient cesa $3^{\text {jes }}$ mutants have larger pore widths and less anisotropic cellulose organization in the closed state (Rui and Anderson, 2016). The role of hemicellulose, namely xyloglucan in Arabidopsis, has been highlighted by the finding that stomata of $x x t 1 x x t 2$ mutants lacking xyloglucan exhibit smaller pore widths in both open and closed states (Rui and Anderson, 2016). Several reports have found evidence for the role of pectins in controlling the elasticity of guard cell walls and the dynamic range of stomata (Jones et al., 2003, 2005; Amsbury et al., 2016; Rui et al., 2017).

Despite extensive investigations of stomatal development (Pillitteri and Torii, 2012) and physiology (Kim et al., 2010), the precise relationships between the structure and composition of guard cell walls and the mechanical function of stomata remain elusive. The mechanics of the plant cell wall can be described by a set of constitutive laws linking extrinsic forces on the wall and its resulting deformation. Hooke's law provides a coherent approach to modeling the elastic behavior of guard cells, i.e., their reversible expansion that disappears when force is removed (DeMichele and Sharpe, 1973; Edwards et al., 1976; Sharpe and Wu, 1978; Franks et al., 1998). To apply Hooke's law to an object with complex geometry and anisotropic mechanical properties, as is the case for guard cell walls, numerical methods should be employed. In previous studies, guard cell shape and dynamics have been modeled using finite element modeling (FEM) (Bathe, 1996; Zienkiewicz et al., 2014) albeit with idealized geometries (Cooke et al., 1976; Wu and Sharpe, 1979; Marom et al., 2017; Woolfenden et al., 2017). Thus, further work is needed to connect the geometries of real stomatal complexes and modeled wall mechanics with stomatal dynamics, in genotypes with normal or altered cell walls.

Here, we examined the contributions of cellulose, xyloglucan, and pectins to the dynamics and mechanical properties of stomatal guard cells of Arabidopsis thaliana. To (1) minimize the effects of idealized geometric assumptions on boundary conditions describing constraints on a stomatal complex, (2) accurately account for the degree of freedom at the stomatal junction area, and (3) pinpoint locations and areas where guard cells interact with neighboring cells, we modeled stomatal guard cells using the contours of actual stomata by computationally tracing 3D confocal images of guard cells and inputting these coordinates directly into our FEMs. We created FEMs of stomatal complexes that recapitulate the geometries and dynamics of wild type (Columbia, Col-0) Arabidopsis plants, and three mutant Arabidopsis lines: $c e s a 3^{j e 5}$, which is defective in cellulose synthesis (Desprez et al., 2007); xxt1 xxt2, which lacks the hemicellulose, xyloglucan (Cavalier et al., 2008; Park and Cosgrove, 2012); and PGX1 OE, which overexpresses POLYGALACTURONASE INVOLVED IN EXPANSION1 (PGX1) and has pectic homogalacturonan (HG) with a smaller average molecular mass (Xiao et al., 2014). In these FEMs, guard cell walls were modeled as geometrically continuous shells of varying thickness with anisotropic mechanical properties. Through simulation of stomatal opening via turgor pressure increase, we identified sets of anisotropic mechanical properties in our FEMs that match observed stomatal geometries in the open state, including stomatal pore width, stomatal complex length, and guard cell width (Figure 1). By comparing anisotropic stiffness coefficients of guard cell walls in different genotypes with knowledge of their molecular composition and structures, this study reveals potential mechanisms by which major wall polysaccharides contribute to the mechanical regulation of stomatal opening and closure.

\section{MATERIALS AND METHODS}

\section{Plant Materials and Growth Conditions}

Arabidopsis thaliana seeds of the Col-0 ecotype, and mutants cesa3je5 (Desprez et al., 2007), xxt1 xxt2 (Arabidopsis Biological Resource Center stock no. CS16349) (Cavalier et al., 2008), and PGX1 OE (Xiao et al., 2014) were surface sterilized in $30 \%$ bleach with $0.1 \%$ SDS for $20 \mathrm{~min}$, washed in sterile water four times, and stored in $0.15 \%$ agar at $4{ }^{\circ} \mathrm{C}$ for at least $2 \mathrm{~d}$ for stratification before sowing on $1 / 2 \mathrm{MS}$ plates $(2.2 \mathrm{~g} / \mathrm{L}$ Murashige and Skoog salts, $0.6 \mathrm{~g} / \mathrm{L}$ MES, pH 5.6) containing $1 \% \mathrm{w} / \mathrm{v}$ sucrose and germinating at $22^{\circ} \mathrm{C}$ under $24 \mathrm{~h}$ illumination in a Percival CU36-L5 growth chamber. Ten-d-old seedlings were transferred from plates to Fafard C2 Soil supplemented with Miracle-Gro and grown at $22^{\circ} \mathrm{C}$ under $16 \mathrm{~h}$ light $/ 8 \mathrm{~h}$ dark conditions.

\section{Estimation of Guard Cell Wall Thickness}

Trimming, fixation, serial dehydration, LR White infiltration and polymerization were performed as described in Amsbury et al. (2016). Two $\mu \mathrm{m}$-thick sections of each leaf sample were cut on a Leica UC6 ultramicrotome (Buffalo Grove, IL) with a glass knife. Sections were stained with $0.05 \%$ toluidine blue for $10-30 \mathrm{~s}$ and rinsed with water to remove excess toluidine blue. Sections were then imaged with the transmission light on a Zeiss Axio Observer microscope with a 100X 1.4 numerical aperture immersion oil objective and a Nikon D5100 DSLR camera. Images were analyzed in ImageJ. Because guard cell walls are differentially thickened (Zhao and Sack, 1999), wall thickness was measured at five different regions for a given guard cell, including the lower periclinal wall, the upper periclinal wall at cuticular ledges, the upper periclinal wall away from cuticular ledges, the ventral wall, and the dorsal wall. Representative images of toluidine blue-stained cross sections of guard cells are presented 

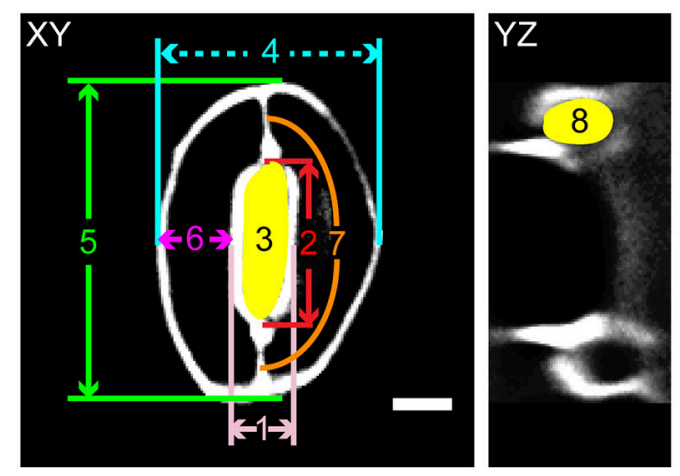

1 stomatal pore width

2 pore length

3 pore area

4 stomatal complex width

5 stomatal complex length

6 guard cell width

7 guard cell arc length

8 junctional area

FIGURE 1 | Legend of measurements in a stomatal complex from 3D confocal imaging of propidium iodide-stained samples. Scale bar is $5 \mu \mathrm{m}$.

in Supplemental Figure 1, and measurements of guard cell wall thickness at these regions are presented in Supplemental Table 1.

\section{Propidium lodide Staining and Confocal Microscopy}

Rosette leaves were collected from 3- to 4-week-old plants. Stomatal opening was induced by incubating leaves in a buffer containing $20 \mathrm{mM} \mathrm{KCl}, 1 \mathrm{mM} \mathrm{CaCl}$, and $5 \mathrm{mM} \mathrm{MES-KOH,} \mathrm{pH}$ 6.15 , in light at $22^{\circ} \mathrm{C}$ in a Percival CU36-L5 growth chamber for $2.5 \mathrm{~h}$. Stomatal closure was induced by incubating leaves in a buffer containing $50 \mathrm{mM} \mathrm{KCl}, 0.1 \mathrm{mM} \mathrm{CaCl}_{2}$, and $10 \mathrm{mM}$ MES- $\mathrm{KOH}, \mathrm{pH} 6.15$, in the dark at $22^{\circ} \mathrm{C}$ in a Percival CU36L5 growth chamber for $2.5 \mathrm{~h}$. Leaves were then stained with $100 \mu \mathrm{g} / \mathrm{ml}$ propidium iodide (PI, Life Technologies; catalog no. P3566) for 5 min before imaging. Z-stack images were collected on a Zeiss Axio Observer microscope with a Yokogawa CSU-X1 spinning disk head and a 63X 1.4 numerical aperture immersion oil objective, using a $561 \mathrm{~nm}$ excitation laser and a $617 / 73 \mathrm{~nm}$ emission filter with a step size of $0.2 \mu \mathrm{m}$. Z-stack images were subjected to 3D blind deconvolution using AutoQuant X2 (Media Cybernetics) software.

\section{Semi-computerized Geometry Measurements of Guard Cells and Stomatal Pores}

A semi-computerized active contours-based method was adopted to segment and measure the pore and cell-pair areas (Kass et al., 1988). In this approach, the user initializes a closed curve by entering a few points. The initialized curve expands and evolves according to the edge map of the image, fitting to the irregularly shaped object. The evolution is driven by an optimization scheme where the cost is minimized when the curve fits the edges smoothly.

Pore area values across each $\mathrm{z}$-stack were obtained via the aforementioned method. To account for outliers due to contrast issues, a robust nonlinear regression (fourth-order polynomial) was applied on the area profile graph, where the variance was assumed to have a Cauchy distribution (Motulsky and Brown, 2006). The minimum of the regression curve was picked as the pore area in number of pixels. As the physical area of a pixel in the XY plane is $0.0409 \mu \mathrm{m}^{2}$, the pore area in pixels was multiplied by this number to obtain the actual area. A connected component analysis was carried out for minimum pore area segmentation. The major and minor axes of the connected component were computed to measure the height and the width of the pore area, respectively.

A similar analysis was administered for cell geometry measurements. Active contours segmentation was carried out to obtain stomatal complex length and width in the image slice that contained the minimum pore area, or another slice within a fourslice neighborhood, where contrast for guard cell perimeters was clearer. The same connected component analysis was conducted to measure stomatal complex length and width.

After obtaining binary masks for cell and pore area, the tangential length of each cell was computed. For this task, intensity profile analysis in the radial direction originating from the center of mass for the pore opening was conducted at each angle within the interval $\left[0^{\circ}, 359^{\circ}\right]$. The local intensity maxima representing pore and cell borders were detected and the midpoint of the line segment between the two points was calculated. This method provided a medial axis for each cell within the pair. The medial axis was smoothed through the Savitzky-Golay filter, where subsets of data were re-fit via polynomial least squares (Savitzky and Golay, 1964). The medial axis curves were simplified through polynomial approximation to minimize meandering and jitter. The arc length of the simplified medial axis was computed to measure the tangential length of individual cells.

\section{Construction of Finite Element Models of Guard Cell Pairs}

Three-dimensional representations of guard cells were generated by tracing the midpoints of guard cell walls from 3-week-old rosette leaves in Col-0, cesa $3^{j e 5}, x x t 1 x x t 2$, and PGX1 OE plants stained with PI to label cell walls. Z-stack images of stomatal complexes in the closed state induced by dark treatment were imported into Vaa3d (Peng et al., 2010) to be traced and landmarked along the middle plane of the guard cell wall (Figure 2C). To ensure the smoothness of the eventual model, traced landmarks were fed to create parameterized 


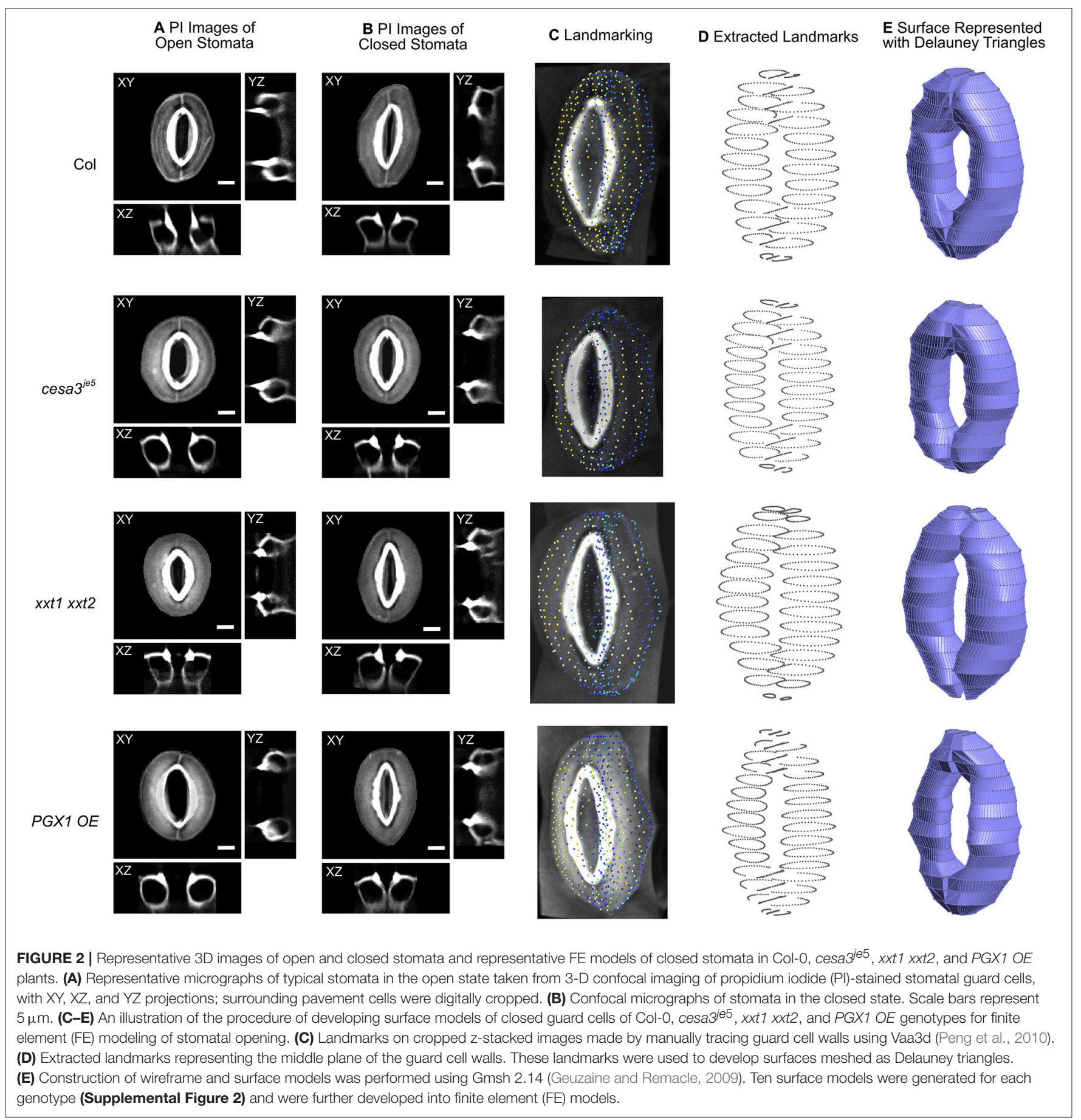

B-spline representations using "splprep" (Dierckx, 1982) in the NumPy library (Jones et al., 2001). Three-dimensional vertices were extracted from the B-spline curve to produce loop elements representing segments of a guard cell wall. Finally, this information was processed to produce triangular elements using Gmsh 2.14 (Geuzaine and Remacle, 2009) as illustrated in Figure 2D. These triangular elements were used to develop finite element models of stomatal complexes that are constructed with shell elements, including mechanical interactions with neighboring cells, using Abaqus (Dassault Systèmes, 2016). The triangular, three-node conventional stress/displacement reduced-integration element "S3R" was used to calculate changes in guard cell wall under applied turgor pressures (Dassault Systèmes, 2016). Interactions with pavement cells were modeled as displacement boundary conditions using experimentally observed changes in stomatal 
TABLE 1 | Measurement of stomatal pore dimensions, guard cell pair dimensions, guard cell junction area, and guard cell geometry in wild type (Col-0), cesa3 ${ }^{\text {e } 5}$, $x x t 1$ $x x t 2$, and $P G X 1 O E$ plants from 3D imaging.

\begin{tabular}{|c|c|c|c|c|c|c|c|c|c|c|}
\hline Treatment & Genotype & $\begin{array}{c}\text { Avg } \\
\text { stomatal } \\
\text { pore width } \\
(\mu \mathrm{m})\end{array}$ & $\begin{array}{c}\text { Avg } \\
\text { stomatal } \\
\text { pore length } \\
(\mu \mathrm{m})\end{array}$ & $\begin{array}{l}\text { Avg aspect } \\
\text { ratio of } \\
\text { pores }\end{array}$ & $\begin{array}{c}\text { Avg pore } \\
\text { area }\left(\mu \mathrm{m}^{2}\right)\end{array}$ & $\begin{array}{c}\text { Avg } \\
\text { stomatal } \\
\text { complex } \\
\text { length }(\mu \mathrm{m})\end{array}$ & $\begin{array}{c}\text { Avg } \\
\text { stomatal } \\
\text { complex } \\
\text { width }(\mu \mathrm{m})\end{array}$ & $\begin{array}{c}\text { Avg guard } \\
\text { cell } \\
\text { junction } \\
\text { area }\left(\mu \mathrm{m}^{2}\right)\end{array}$ & $\begin{array}{l}\text { Avg guard } \\
\text { cell width } \\
(\mu \mathrm{m})\end{array}$ & $\begin{array}{c}\text { Avg guard } \\
\text { cell arc } \\
\text { length }(\mu \mathrm{m})\end{array}$ \\
\hline \multirow[t]{4}{*}{ darkness (closed) } & Col-O & $1.2 \pm 0.1^{\mathrm{a}}$ & $11.9 \pm 0.4^{a}$ & $0.10 \pm 0.01^{a}$ & $12.6 \pm 1.1^{a}$ & $24.5 \pm 0.5^{a b}$ & $14.8 \pm 0.3^{a}$ & $49.9 \pm 1.6^{a}$ & $6.5 \pm 0.2^{a}$ & $20.7 \pm 0.4^{\mathrm{a}}$ \\
\hline & cesa3 $^{j e 5}$ & $2.5 \pm 0.2^{b}$ & $11.2 \pm 0.4^{a}$ & $0.23 \pm 0.01^{b}$ & $24.6 \pm 1.6^{b}$ & $22.9 \pm 0.5^{\mathrm{a}}$ & $15.2 \pm 0.4^{a}$ & $46.6 \pm 1.3^{a}$ & $6.2 \pm 0.2^{a}$ & $22.6 \pm 0.6^{b c}$ \\
\hline & $x x t 1 \quad x x t 2$ & $0.6 \pm 0.1^{c}$ & $12.2 \pm 0.4^{a}$ & $0.05 \pm 0.01^{c}$ & $7.1 \pm 1.0^{\mathrm{C}}$ & $24.8 \pm 0.5^{b}$ & $14.4 \pm 0.2^{a}$ & $46.1 \pm 0.9^{a}$ & $6.3 \pm 0.2^{a}$ & $19.7 \pm 0.3^{\mathrm{ac}}$ \\
\hline & $P G \times 1 O E$ & $0.7 \pm 0.1^{c}$ & $12.4 \pm 0.3^{a}$ & $0.06 \pm 0.01^{c}$ & $10.3 \pm 1.2^{\mathrm{ac}}$ & $25.1 \pm 0.4^{b}$ & $13.0 \pm 0.3^{b}$ & $46.4 \pm 1.0^{a}$ & $5.9 \pm 0.1^{a}$ & $22.2 \pm 1.3^{a}$ \\
\hline \multirow[t]{4}{*}{ light(open) } & Col-O & $3.9 \pm 0.2^{a}$ & $13.6 \pm 0.5^{a}$ & $0.30 \pm 0.02^{\mathrm{ac}}$ & $42.3 \pm 2.6^{a}$ & $25.4 \pm 0.5^{\mathrm{a}}$ & $16.9 \pm 0.3^{a}$ & $44.1 \pm 0.9^{a}$ & $6.5 \pm 0.1^{a}$ & $24.0 \pm 0.3^{a}$ \\
\hline & cesa3 $^{j e 5}$ & $4.7 \pm 0.4^{a}$ & $10.0 \pm 0.9^{b c}$ & $0.48 \pm 0.03^{b}$ & $41.8 \pm 4.8^{\mathrm{a}}$ & $22.7 \pm 0.5^{\mathrm{bc}}$ & $18.1 \pm 0.3^{a}$ & $48.0 \pm 0.9^{b}$ & $6.7 \pm 0.1^{a}$ & $23.3 \pm 0.5^{\mathrm{a}}$ \\
\hline & $x x t 1 \quad x x t 2$ & $2.3 \pm 0.2^{b}$ & $8.5 \pm 0.6^{c}$ & $0.29 \pm 0.02^{\mathrm{C}}$ & $17.5 \pm 2.0^{b}$ & $21.8 \pm 0.5^{b}$ & $15.2 \pm 0.2^{b}$ & $45.2 \pm 1.0^{a b}$ & $6.5 \pm 0.1^{a}$ & $20.0 \pm 0.3^{a}$ \\
\hline & $P G \times 1 O E$ & $4.5 \pm 0.2^{a}$ & $12.0 \pm 0.5^{a b}$ & $0.38 \pm 0.02^{\mathrm{a}}$ & $45.6 \pm 3.7^{a}$ & $24.3 \pm 0.5^{\mathrm{ac}}$ & $18.0 \pm 0.4^{a}$ & $45.6 \pm 1.0^{a b}$ & $6.8 \pm 0.1^{a}$ & $24.4 \pm 0.5^{b}$ \\
\hline
\end{tabular}

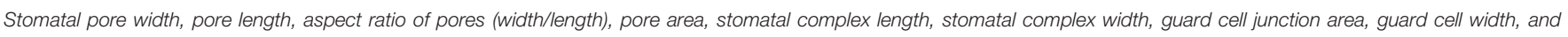

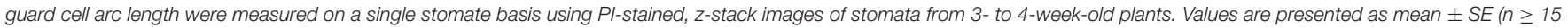

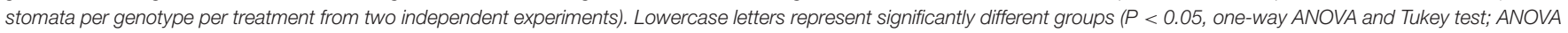
was performed within each treatment).

complex length and stomatal complex width (Figure 1 and Table 1). These prescribed boundary conditions resulted in additional loading on stomatal junction areas and dorsal areas, respectively.

Considering the large amount of deformation that stomatal guard cells undergo during opening and closing, geometric nonlinear analysis was used. The guard cell wall was modeled to be a linear, orthotropic, elastic material. Because guard cell walls undergo repeated, reversible deformations, no plastic deformation was assumed. Therefore, sets of optimal elastic properties, which resulted in final stomatal geometries that matched the measured values of open stomata (Table 1), were sought by examining a full factorial combination of mechanical properties of orthotropic elasticity. The elastic mechanical properties of the guard cell wall were defined by three orthogonal axes representing longitudinal (polar, $E_{1}$ ), circumferential (azimuthal, $E_{2}$ ), and thickness (radial, $E_{3}$ ) directions, as well as by shear moduli between two axes, including $G_{12}, G_{13}$, and $G_{23}$, respectively (Supplemental Figures 3, 4). To describe stiffness in three directions relevant to the guard cell wall, the orientation of material properties was defined to reflect the arrangement of cellulose microfibrils in stomatal complexes (Supplemental Figure 4).

Poisson's ratio of the outer wall in onion epidermal fragments has been estimated to be approximately 1 from the movement of individual cellulose microfibrils (Zhang et al., 2017). However, Poisson's ratio for whole plant cell walls has yet to be experimentally determined. Here, Poisson's ratio of the guard cell wall was estimated using a cell wall network model (Yi and Puri, 2012) with simulated orthogonal deformation relative to the loading direction. Poisson's ratio determined for five network models of cell walls (Yi and Puri, 2012) is 0.003, which was assigned for all directions and was not varied in the process of finding optimal elastic properties, since in our FEMs, modulating Poisson's ratio between 0 and 0.49 had negligible effects on modeled stomatal geometries $(p>0.05$, Mann-Whitney-Wilcox test).

In addition, thicknesses of guard cell walls were assigned based on their locations using thickness measurements of guard cell walls (Supplemental Table 1). Changes in wall thickness along the longitudinal axis of guard cells were deduced from images from Zhao and Sack (1999).

For full factorial analysis of cell wall properties, elastic properties were varied to be $200 \mathrm{kPa}, 200 \mathrm{MPa}$, and $200 \mathrm{GPa}$, representing the widest range of possible cell wall stiffnesses. For example, $200 \mathrm{GPa}$ represents a maximum stiffness value reported for crystalline cellulose based on density functional calculations (Nishiyama et al., 2008; Cintrón et al., 2011; Quesada Cabrera et al., 2011; Dri et al., 2013; Wu et al., 2013). On the opposite extreme, $200 \mathrm{kPa}$ represents minimum reported stiffness values for plant cell assemblies under extension (Vanstreels et al., 2005; Zamil et al., 2014, 2015; Kim et al., 2015). Finally, (Wei and Lintilhac, 2007) reported moduli of cell walls to range from 213 MPa for young samples to $360 \mathrm{MPa}$ for older samples. Therefore, the modulus of $200 \mathrm{MPa}$ was chosen as a value in between the other two bounding values.

Based on these three levels of elastic modulus values, we created models of guard cell walls with full factorial combinations of Young's modulus in three orthogonal directions, namely $\mathrm{E}_{1}$ (polar), $\mathrm{E}_{2}$ (azimuthal), and $\mathrm{E}_{3}$ (radial), and three shear moduli, namely $G_{12}, G_{23}$, and $G_{13}$. Inclusion of shear modulus accounts for the guard cell wall's change in shape that can significantly constrain its mechanical deformation. Based on pressure probe data for Vicia faba guard cells (Franks et al., 1998, 2001), a $5 \mathrm{MPa}$ turgor increase was imposed to simulate opening of stomatal complex FEMs in 4 genotypes, with 10 models for each genotype and 729 different combinations of elastic moduli. The combinations of mechanical properties that resulted in open stomatal geometries that were closest to the observed stomatal geometries were further refined for each genotype using 
Broyden's method (Broyden, 1965) with respect to pore width (Figure 2A and Supplemental Movie 1).

We did not aggregate target guard cell geometries, because different stomatal geometries exhibited different sensitivity to different elastic moduli. This strategy differs from approaches used by recently published studies (Carter et al., 2017; Marom et al., 2017; Woolfenden et al., 2017) in which a single, simplified stomatal complex was modeled. In our approach, multiple imaging-derived FEMs were generated for each genotype, and an orthotropic material model was chosen to reflect the anisotropic nature of plant cell walls in all three orthogonal directions. Our approach inherently considers biological variability in the shape and size of stomatal complexes and, therefore, is free of potential confounding effects from simplifications of stomatal complex geometry. Typically, simulated stomatal geometries were within $10 \%$ of experimentally measured geometries.

\section{Statistical Analysis}

Statistical analyses of experimentally observed data were performed using the PAST statistics software package (Hammer et al., 2008). Statistical analyses of computational modeling results were performed using R (Ver. 3.3.2, R Core Team, 2016). Comparisons of measured and modeled stomatal geometries, including pore width, pore area, stomatal complex length, and guard cell width were conducted with Mann-Whitney-Wilcox tests. Effects of genotype on closed and open stomatal geometries were analyzed using ANOVA and Tukey tests. Graphics were produced with the ggplot2 package (Wickham, 2009) within the R environment.

\section{RESULTS}

\section{From 3D Imaging to 3D Modeling of Stomata}

To capture stomatal shape in three dimensions, we used propidium iodide (PI) to stain intact leaves of Col-0, cesa $3^{j e 5}, x x t 1$ $x x t 2$, and PGX1 OE genotypes that had been treated with light or darkness to induce stomatal opening or closure, respectively. We then collected $z$-stack confocal images of stomata, which allowed us to generate $\mathrm{XY}, \mathrm{XZ}$, and $\mathrm{YZ}$ projections of single stomatal complexes (Figures 2A,B, Supplemental Movies 1, 2). Next, we traced along the midpoints of cell walls from the z-stack images of closed stomata of each genotype to extract landmarks (Figures 2C,D). Midpoints were traced from YZ projections and served as the scaffolds of our FEMs (Figure 2E). FE shell elements were defined with vertices representing the midpoint of the thickness of the guard cell wall. Because guard cell walls are differentially thickened (Zhao and Sack, 1999), we measured wall thickness at five different regions of a guard cell (Supplemental Figure 1 and Supplemental Table 1) and assigned these thickness values to the FE shell elements corresponding to each region. This approach enabled us to quantitatively investigate geometric changes during stomatal opening and to model interactions between guard cells and surrounding pavement cells without inserting idealizations or assumptions about the sizes and shapes of stomatal complexes (Franks et al., 1998, 2001).
To account for biological variability between stomata, ten stomatal complexes per genotype in the closed state were used to extract landmarks (Supplemental Figure 2). Using multiple stomatal complex FEMs increased the required computational resources but relieved a need for the introduction of mathematical averaging or variability calculations to account for the inherent variability of guard cell shape and size in real plants.

In our FEMs of open stomata (Figure 2E), stomatal pore geometries and guard cell geometries were calculated (Supplemental Table 2). Stomatal pore geometry includes pore width (aperture), pore length, and pore area (Figure 1). Guard cell geometry includes guard cell width and guard cell arc length (Figure 1). Measured geometries from 3D z-stack images of stomata in the open state (Figure 2A and Supplemental Movie 1) are listed in Table $\mathbf{1}$ and were used to validate FE modeling results (Supplemental Table 2).

\section{Effects of Simplifying Stomatal Complex Geometry on Stomatal Opening}

To examine how simplifying stomatal geometry affects the modeling of stomatal dynamics, we constructed a simplified model with following assumptions: (1) stomata open upon a $5 \mathrm{MPa}$ turgor pressure increase, (2) guard cell wall thickness is $0.5 \mu \mathrm{m}$, (3) guard cell wall deformation is influenced by transverse shear deformation (thick shell model), (4) the guard cell wall is elastic, meaning that a stomatal complex recovers its original shape when guard cells are not turgid, and (5) there is no preemptively imposed symmetry, allowing for anisotropy in the guard cell wall in all directions. In addition, considering that the deformation of a stomatal complex is much larger than one percent of the original dimensions, the secondary effects of large deformations were considered (non-linear elasticity). In a simplified stomatal complex model, an ellipse and an elliptical torus (Woolfenden et al., 2017) were used to represent the stomatal pore and the guard cell pair, respectively (Figure 3).

Based on previous findings of the anisotropic behavior of stomatal guard cells (Cooke et al., 1976; Meckel et al., 2007; Woolfenden et al., 2017) and considering our stomatal measurements (Table 1), we also assumed that the guard cell wall is mechanically anisotropic. Specifically, considering the circumferential arrangement of cellulose microfibrils (Zhao and Sack, 1999), an "orthotropic isotropy" was assumed, which means that cell wall stiffness exhibits elastic symmetry with respect to three orthogonal planes. In our simplified stomatal complex models, the mechanical properties of Arabidopsis guard cell walls estimated by Woolfenden et al. (2017) were converted to values for orthotropic moduli. These values are listed in Table 2.

When opening of a geometrically simplified stomatal complex was simulated using the initial dimensions reported in Woolfenden et al. (2017) as shown in Figure 3A, stomatal pore width increased from 0.9 to $1.8 \mu \mathrm{m}$ (Figure 3B). Considering that simple linear elasticity was used to model cell wall mechanics and that the converted modulus values do not involve hyperelasticity theory, this $10 \%$ underestimation is remarkably close to the results of Woolfenden et al. (2017). However, when a guard 
A

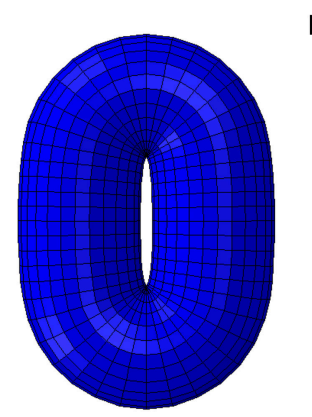

B

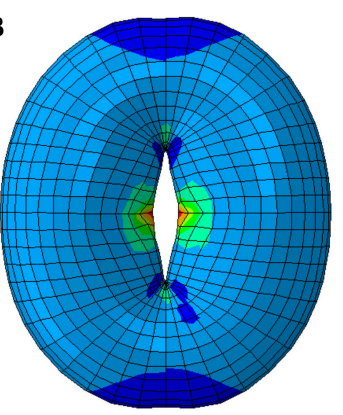

von Mises

Stress

(MPa)

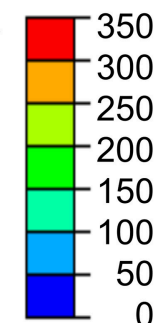

C

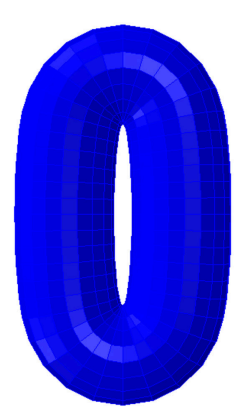

D

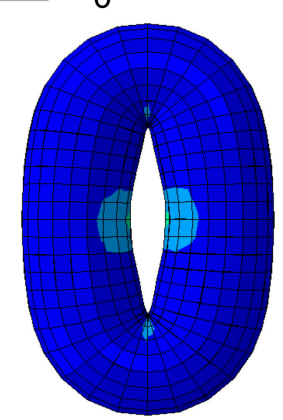

FIGURE 3 | Stomatal opening simulation using a simplified guard cell model constructed as a torus using an elliptical stomatal pore profile when closed. (A) Stomatal guard cell model with a simplified geometric representation as a torus according to the reported Arabidopsis wild-type geometry in Woolfenden et al. (2017). (B) When stomatal opening is modeled in accordance with guard cell wall properties reported in Woolfenden et al. (2017), stomatal opening is slightly (10\% based on the open pore width) underestimated. (C) Stomatal guard cell model with a simplified geometric representation as a torus according to the observed Col-0 (Table 1). (D) When this is modeled in accordance with guard cell wall properties reported in Woolfenden et al. (2017), stomatal opening is underestimated ( $40 \%$ based on the open pore width).

cell pair was modeled with simplified geometry (ellipse plus elliptical torus) but also with initial dimensions taken from actual stomatal complexes (Table 1) as shown in Figure 3C, stomatal pore width increased from 1.2 to $2.3 \mu \mathrm{m}$ (Figure 3D). This is a $41 \%$ underestimation when compared to observed stomatal geometries (Table 1).

\section{Effects of Pavement Cell Constraints on Stomatal Opening}

Another important aspect of a stomatal complex is its interaction with pavement cells. To isolate the effects of pavement cell constraints on stomatal dynamics, stomatal opening was modeled with realistic models of stomatal complexes of

TABLE 2 | Engineering elastic constants equivalent to Woolfenden et al. (2017)'s mechanical properties for wild-type Arabidopsis (All values are in $\mathrm{MPa}, 10^{6} \mathrm{~N} / \mathrm{m}^{2}$ ).

\begin{tabular}{lcccccc}
\hline Genotype & $\boldsymbol{E}_{\mathbf{1}}$ & $\boldsymbol{E}_{\mathbf{2}}$ & $\boldsymbol{E}_{\mathbf{3}}$ & $\boldsymbol{G}_{\mathbf{1 2}}$ & $\boldsymbol{G}_{\mathbf{1 3}}$ & $\boldsymbol{G}_{\mathbf{2 3}}$ \\
\hline Col-0 & 99 & 601 & 601 & 33 & 33 & 33 \\
\hline
\end{tabular}

Poisson's ratio (v) was assigned to be 0.2 to ensure the positive strain energy and determinant of the compliance matrix.

Arabidopsis Col-0 that were based on measured stomatal geometries (Figure 2). The mechanical properties of the guard cell walls were consistent with those in the simplified stomatal complex models (Figure 3).

Stomatal opening was first modeled without any constraints around the stomatal complex. Next, stomatal opening was modeled using observed stomatal complex widths and lengths under closed and open conditions (Table 1) as constraints.

The importance of pavement cell constraints on a stomatal complex is illustrated in Figure 4. Figure 4A shows an underestimation in stomatal opening when no constraint was included, but when observed stomatal complex widths and lengths were incorporated as size constraints on the stomatal complex due to mechanical constraints imposed by neighboring pavement cells, stomatal pore width increased significantly upon simulated pressurization of $5 \mathrm{MPa}$ (Figure 4B; $p<0.05$, Mann-Whitney-Wilcox test).

\section{Effects of Modified Wall Composition on Stomatal Geometry}

Geometric parameters of stomata, including pore width, pore length, pore aspect ratio (width/length), pore area, stomatal complex length, stomatal complex width, guard cell arc length, guard cell width, and guard cell junction area (Figure 1 and Table 1), were determined computationally or manually from experimentally acquired images of PIstained stomatal complexes, depending on the accuracy of computational segmentation as benchmarked against subsets of manual measurements. Three-dimensional features, such as the irregular border of a stomatal pore, were taken into account in our measurements, since pore shape did not conform to idealized geometries (e.g., an ellipse or a symmetric lens). Computational image analysis enabled bias-free measurements of geometry. Both our computational and manual image analyses searched for the narrowest stomatal pore width (Figure 5), and the largest dimensions for stomatal complex length, stomatal complex width, and guard cell arc length (Figure 6) throughout the 3D space occupied by the actual stomatal complex.

When comparing measurements of stomatal pore geometry across genotypes (Table 1), the trends of pore width changes using the $3 \mathrm{D}$ confocal image datasets were consistent with what we have previously observed in 2D brightfield image datasets (Rui and Anderson, 2016): cesa3 $3^{j e 5}$ stomata had larger pore widths, whereas $x x t 1 x x t 2$ stomata exhibited smaller pore widths, than wild type controls in the open or closed state (Table 1) (Rui and 

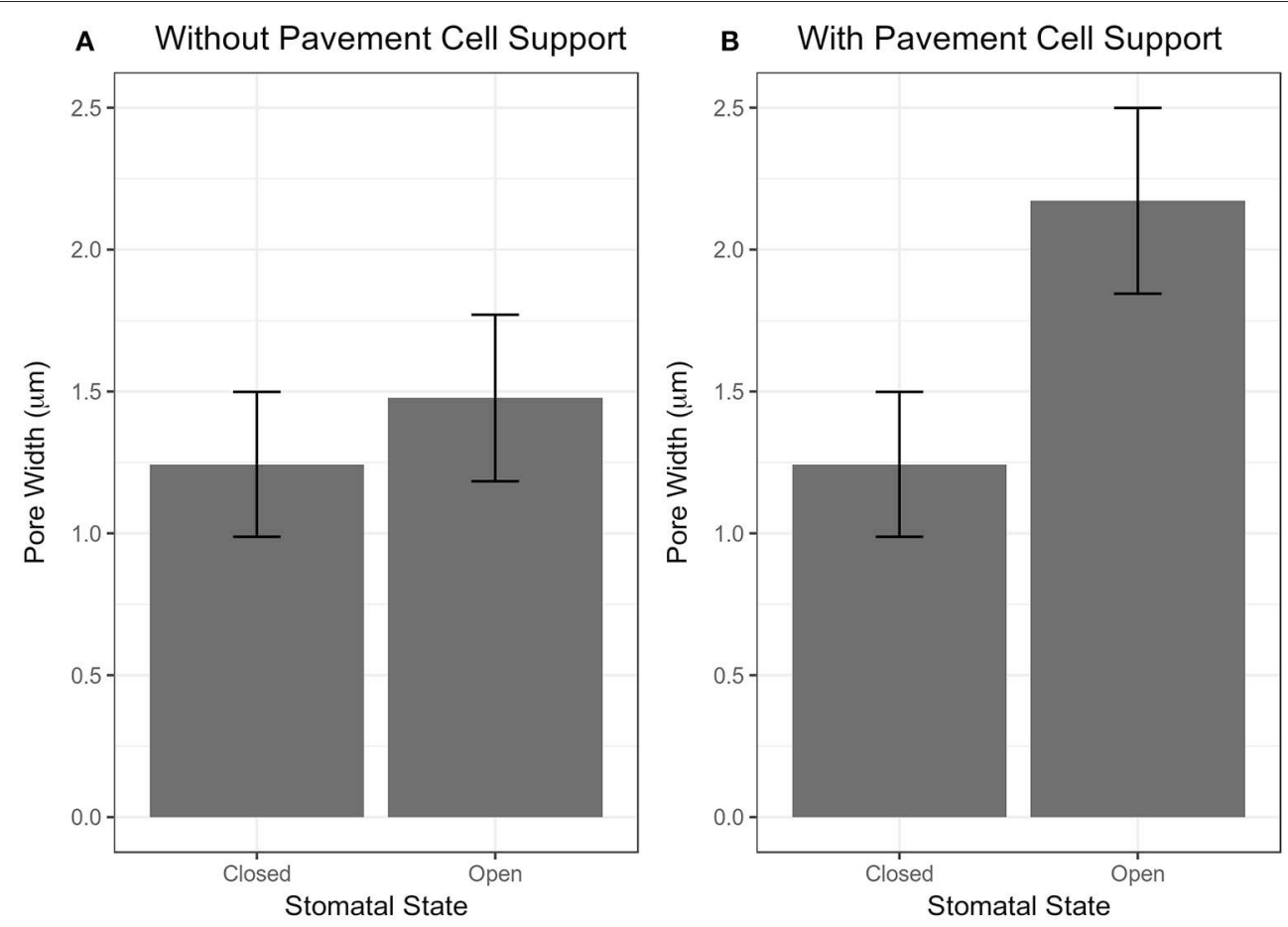

FIGURE 4 | Results of stomatal opening simulation with realistic stomatal complex models of Arabidopsis Col-0 without (A) and with (B) mechanical support from neighboring pavement cells. Simulated opening of traced stomatal FE models was performed using wall mechanical properties equivalent to Woolfenden et al. (2017) (Table 2).

Anderson, 2016). PGX1 OE stomata showed the greatest increase in pore width, pore aspect ratio, and pore area from the closed state to the open state upon experimentally induced opening, whereas $x x t 1 x x t 2$ stomata showed the smallest increases in these values among the four genotypes (Table 1 ).

The function of stomata in regulating gas exchange by controlling stomatal conductance (von Caemmerer and Farquhar, 1981) is assumed to be directly related to pore area (Franks and Farquhar, 2001; Franks et al., 2009). Therefore, we performed correlation analyses between pore width and pore area in either closed or open state and found that these two parameters fit in a linear relationship for all four genotypes, regardless of the functional state of the stomata (Supplemental Figure 5).

When comparing measurements across genotypes (Table 1), stomatal complex length showed a significant increase from the closed to the open state in $x x t 1 x x t 2$ mutants, whereas the other genotypes displayed small changes in stomatal complex length between the two functional states. The pattern of changes in stomatal complex width was consistent with the trend of pore width changes, i.e., PGX1 OE plants showed the most increase, whereas $x x t 1$ xxt2 mutants had the least increase in stomatal complex width from the closed state to the open state among all four genotypes (Table 1).

When comparing guard cell junction areas, which were analyzed manually from $\mathrm{YZ}$ projections of $3 \mathrm{D}$ confocal images (Figure 1), we found a significant reduction in guard cell junction area from the closed state to the open state in Col-0 controls, but not in genotypes with altered wall composition (Table 1).

Comparing measured values for guard cell geometry that were not used in constructing our FEMs (Table $\mathbf{1}$ and Figure 7) to modeled values highlights additional mechanical forces in stomatal dynamics. For example, we did not observe significant changes in guard cell width between closed and open stomata in $\mathrm{Col}, c e s a 3^{j e 5}$, or $x x t 1 x x t 2$ from our $3 \mathrm{D}$ confocal image dataset, a finding consistent with $2 \mathrm{D}$ brightfield imaging (Rui and Anderson, 2016), but guard cell width did increase significantly upon opening in PGX1 OE stomata (Figure 7A; $p<0.001$, Mann-Whitney-Wilcox test). Similarly, FEM results showed non-significant changes in guard cell width for Col, cesa $3^{j e 5}$, or $x x t 1 x x t 2(p>0.05$, Mann-Whitney-Wilcox test), but showed a significant increase for PGX1 OE ( $p<0.001$, Mann-WhitneyWilcox test). However, for Col, FEM results significantly overestimated changes in guard cell width compared to experimental measurements $(p=0.01$, Mann-Whitney-Wilcox test).

Compared to guard cell width, guard cell arc length, as measured experimentally, increased significantly from the closed to the open state only for Col-0 and PGX1 OE stomata (Figure 7B). This observation is consistent with previous findings that guard cells elongate to open the stomatal pore (Meckel et al., 2007; Rui and Anderson, 2016). Although FEM results replicated experimental observations for Col, cesa $3^{j e 5}$, and PGX1 OE ( $p>0.05$, Mann-Whitney-Wilcox test), FEM 
A

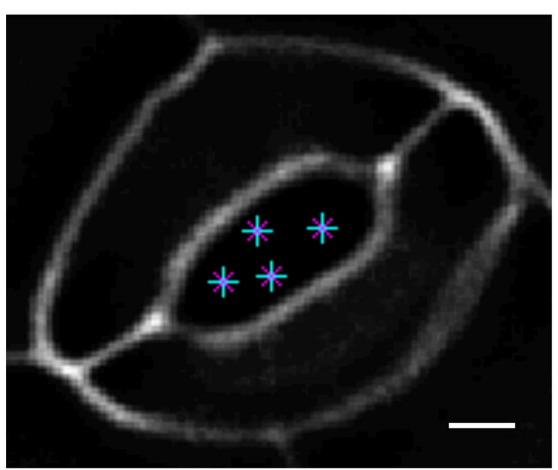

C

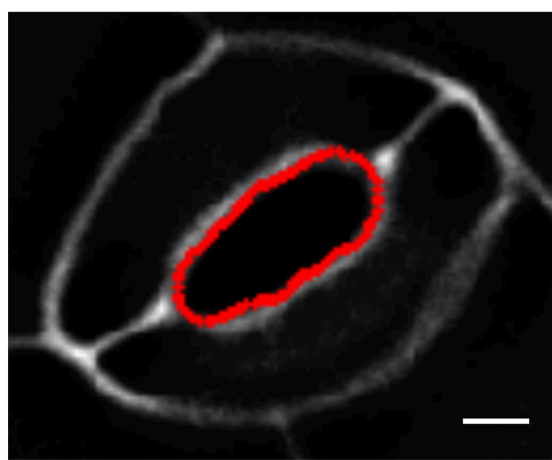

E

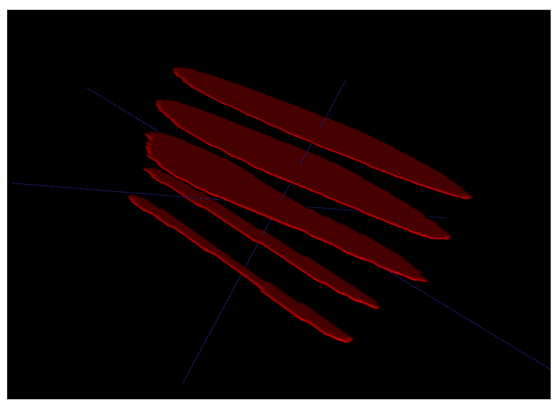

B

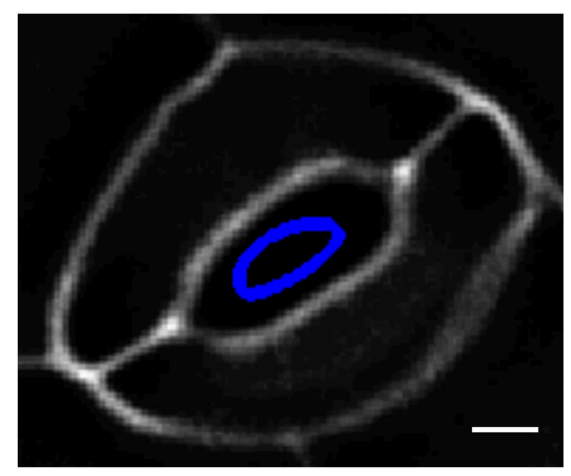

D

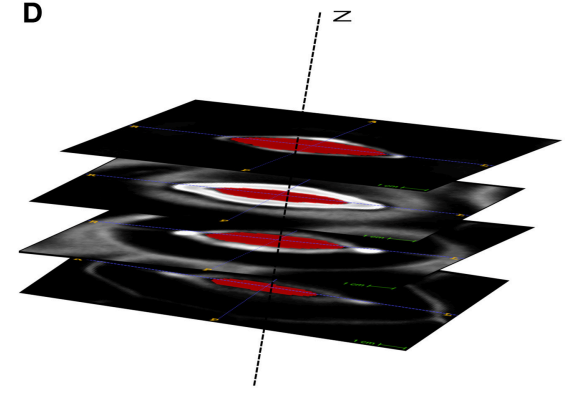

$\mathbf{F}$

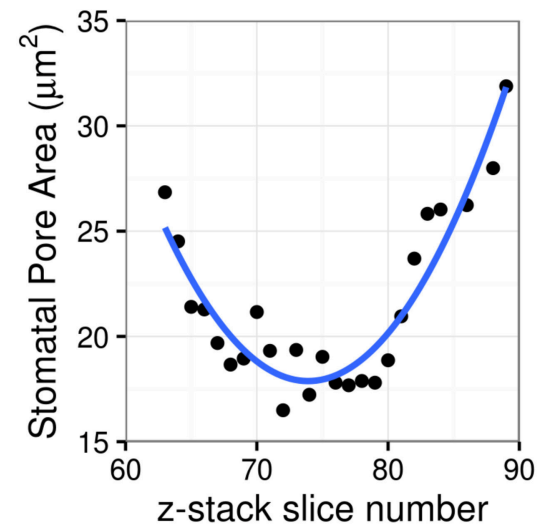

FIGURE $\mathbf{5}$ | Procedure of stomatal pore area measurement. (A) A few points are input by the user on a single slice of the z-stack. (B) A curve is initialized from these points. (C) The curve expands and evolves according to edges in the image and fits the pore opening. (D) Cross-sectional view of detected pore areas after segmentation through a z-stack. (E) Pixel counts within the extracted pore areas are calculated, and the smallest one is converted to pore area in $\mu \mathrm{m}^{2}$. (F) Stomatal pore areas of $z$-stack slices are fitted to a robust quadratic equation to find the respective minimum value representing the pore area of a given stomatal complex. Scale bars represent $5 \mu \mathrm{m}$.

overestimated guard cell arc length in the open state in $x x t 1 \quad x x t 2$ mutants compared to experimental measurements $(p<0.001$, Mann-Whitney-Wilcox test). The fact that guard cell arc length did not increase significantly in experimental measurements of $x x t 1 x x t 2$ or cesa $3^{j e 5}$ stomata, and that discrepancies between measured and modeled arc length existed for $x x t 1 x x t 2$, suggests that guard cell elongation might not be the only driving mechanism for stomatal opening, since stomata opened to at least some degree in all genotypes.

\section{Modeled Mechanical Properties of Guard Cell Walls}

Ranges of mechanical properties resulting in open stomatal geometry that matched experimental observations $(p>0.05$, Mann-Whitney-Wilcox test) are listed in Table 3. These ranges of mechanical properties were identified for stomatal complexes of each genotype when we removed physically impossible sets (i.e., violating symmetry required by orthotropic elasticity) and biomechanically impossible sets (i.e., stiffness higher than the known maximum stiffness of cellulose) (Cintrón et al., 

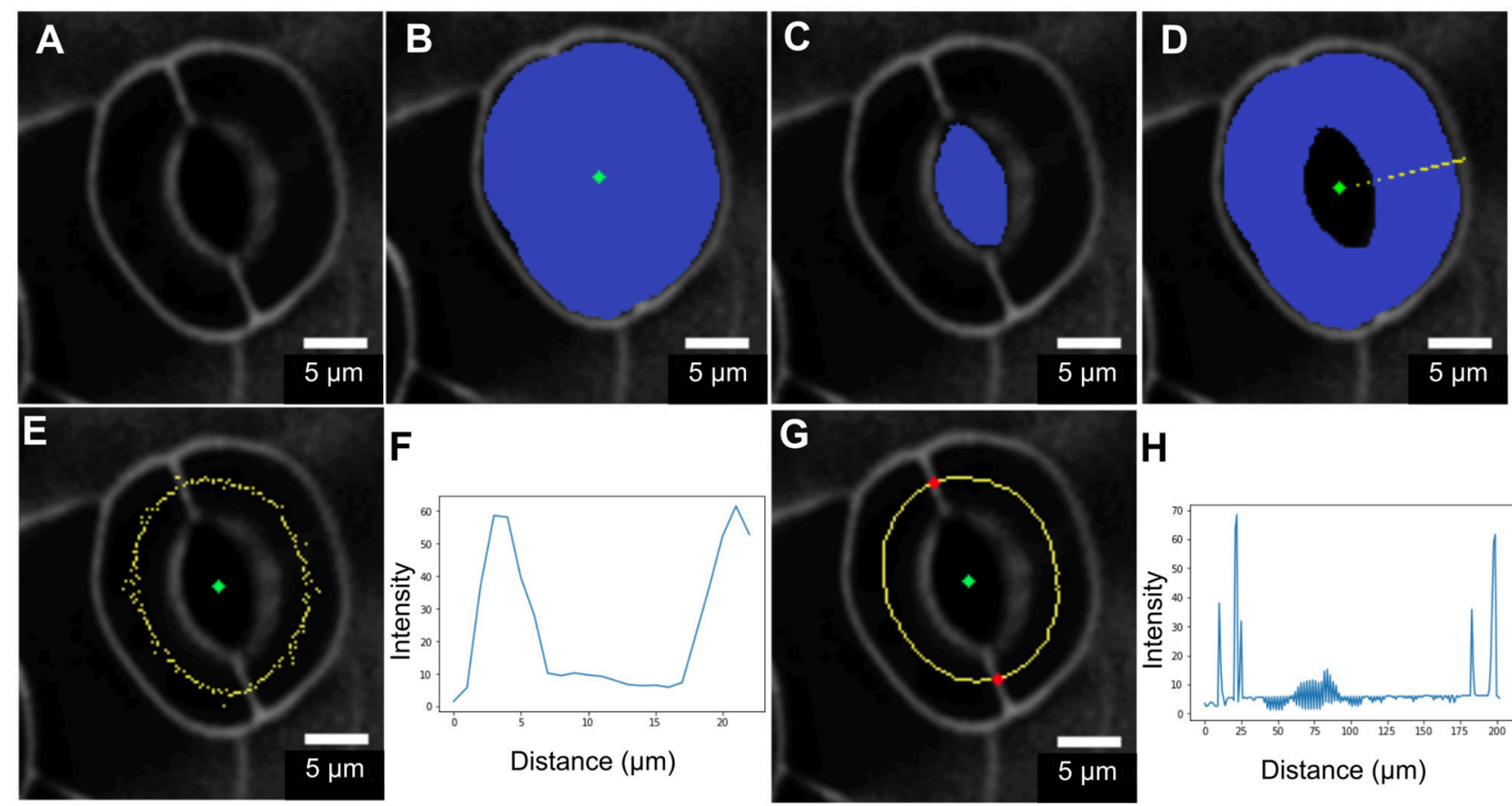

$\mathbf{H}$

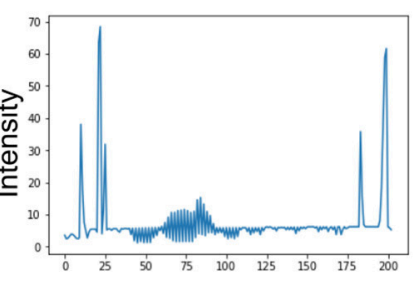

Distance $(\mu \mathrm{m})$

FIGURE 6 | Procedure for measuring guard cell arc length. (A) Original image. (B) Segmentation of the stomatal complex via active contours. (C) Pore area segmentation via active contours. (D) Cell pair area extraction through a binary morphological operation (XOR). (E,F) Non-smooth midline (yellow) calculated between outer cell boundaries and pore boundaries. Intensity profile analysis is in the radial direction. $\mathbf{( G , H ) ~ M i d - p o i n t s ~ a f t e r ~ s m o o t h i n g ~ a n d ~ e d g e - f i l l i n g . ~ J u n c t i o n ~ p o i n t ~}$ detection (red) via intensity profile analysis along the midline.
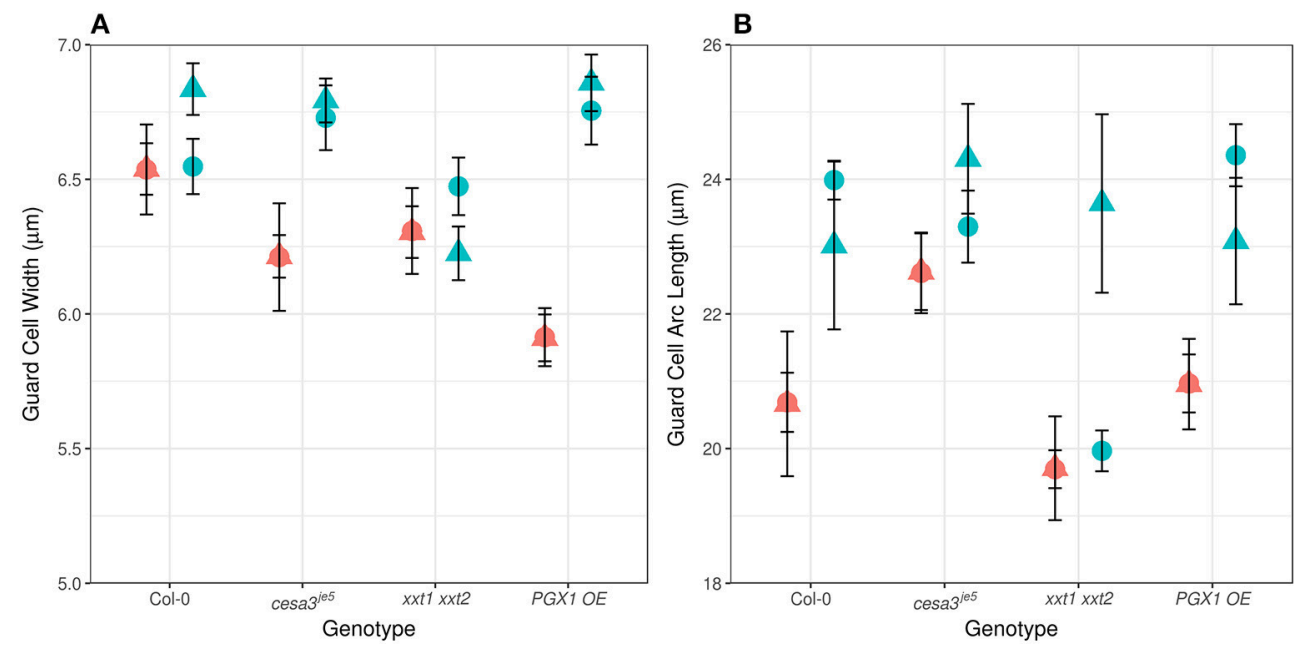

Source

Experiment

Model

State

closed

open

FIGURE 7 | Experimentally observed and computationally predicted guard cell widths and lengths of Col-0, cesa3 ${ }^{\text {je5 }}$, xxt1 xxt2, and PGX1 OE stomata. (A) Error bars represent standard error. Guard cell width $(n>15)$ did not change upon opening for Col-0, cesa $3^{j e 5}$, and $x x t 1$ xxt2 genotypes $(p>0.05$ for all three genotypes, Mann-Whitney-Wilcox test), whereas PGX1 OE showed radial expansion upon opening ( $p<0.001$, Mann-Whitney-Wilcox test). FE simulation ( $n=10$ for each genotype) predicted non-significant radial expansion for Col-0 and xxt1 xxt2 ( $p>0.05$ for both genotypes, Mann-Whitney-Wilcox test) but significant radial expansion for cesa3je5 ( $p=0.052$, Mann-Whitney-Wilcox test) and PGX1 OE ( $p<0.001$, Mann-Whitney-Wilcox test). (B) Guard cell arc length $(n>11)$ changed significantly only for Col-0 and PGX1 OE upon opening ( $p<0.001$, Mann-Whitney-Wilcox test), whereas guard cell arc length did not change significantly for cesa3 ${ }^{j e 5}$ and $x x t 1$ $x x t 2$ stomata $(p>0.05$ for all three genotypes, Mann-Whitney-Wilcox test). However, guard cell arc length in the open state from FE model simulation $(n=10$ for each genotype) did not differ significantly from that in the closed state $(p>0.05$, Mann-Whitney-Wilcox test) except for xxt1 xxt2 ( $p=0.03$, Mann-Whitney-Wilcox test). 
TABLE 3 | Ranges of elastic moduli values including Young's moduli ( $E_{1}, E_{2}$, and $\left.E_{3}\right)$ and shear moduli $\left(G_{12}, G_{13}\right.$, and $\left.G_{23}\right)$ of $F E$ guard cell models that reproduces statistically indistinguishable $\left(p>0.05\right.$ Mann-Whitney-Wilcox test) open stomatal pore width (All values are in $\mathrm{MPa}, 10^{6} \mathrm{~N} / \mathrm{m}^{2}$ ).

\begin{tabular}{|c|c|c|c|c|c|c|}
\hline Genotype & $E_{1}$ & $E_{2}$ & $E_{3}$ & $G_{12}$ & $G_{13}$ & $G_{23}$ \\
\hline Col-0 & $0.01-1(0.5)$ & $0.2-6(2)$ & $0.2-6(2)$ & $5-50(50)$ & $0.1-50(10)$ & $0.1-50(10)$ \\
\hline cesaßje5 & $0.1-10(5)$ & $0.2-25(25)$ & $0.2-25$ (25) & $0.1-10(10)$ & $0.1-10(10)$ & $0.1-10(10)$ \\
\hline$x x t 1 x x t 2$ & $0.0025-0.25(0.0025)$ & $0.0002-0.2(0.0002)$ & $0.0002-0.2(0.0002)$ & $0.25-1(0.25)$ & $0.25-1(0.25)$ & $0.5-2(0.5)$ \\
\hline$P G X 1 O E$ & $0.1-1(0.1)$ & $1-10(10)$ & $1-10(10)$ & $1.5-10(10)$ & $1.5-10(10)$ & $50-750(750)$ \\
\hline
\end{tabular}

Values in parentheses are values of elastic moduli that resulted in open stomatal geometries that were closest to experimental observations.

2011; Quesada Cabrera et al., 2011). The estimated mechanical properties of guard cell walls (Table 2) were within the ranges of experimental measurements of wall mechanical properties (Vanstreels et al., 2005; Peaucelle et al., 2011; Zamil et al., 2013, 2014, 2015), including those generated from nanoindentation experiments such as atomic force microscopy (AFM) (Milani et al., 2011; Peaucelle et al., 2011; Forouzesh et al., 2013; Carter et al., 2017). Furthermore, for each genotype, a single combination of mechanical properties that result in open stomatal geometry to be the closest to experimental observations was identified (values in parentheses of Table 3). The trends of the listed ranges of mechanical properties are consistent with the optimal values. Therefore, for simplicity, optimal values are used in the following sections.

In all genotypes except $x x t 1 x x t 2$, longitudinal modulus $\left(E_{1}\right.$, polar) was smaller than moduli in other directions $\left(E_{2}\right.$, azimuthal and $E_{3}$, radial) (Table 3 ). The anisotropy ratios of $E_{1}$ to both $E_{2}$ and $E_{3}$ were 1:4 and 1:5 for Col-0 and cesa $3^{j e 5}$, respectively. $P G X 1 O E$ required a much higher anisotropy ratio of $E_{1}$ to both $E_{2}$ and $E_{3}$ (1:100) to achieve the observed stomatal opening. For Col-0, it is notable that shear moduli $\left(G_{12}, G_{13}\right.$, and $\left.G_{23}\right)$ were higher than Young's moduli $\left(E_{1}, E_{2}\right.$, and $\left.E_{3}\right)$, which explains the limited amount of circumferential expansion of guard cells during stomatal opening. In addition, a higher $G_{12}$ than $G_{13}$ and $G_{23}$ suggests that the interaction between cellulose and matrix polymers may form preferentially along the longitudinal axes of CMFs, which is the circumferential direction in a guard cell, resulting in similar molecular structures and mechanical properties in the shear planes involving the radial (thickness) direction.

Altered mechanical properties in mutants provided insights into the relationship between their modified wall structures and mechanical behaviors. For cesa $3^{j e 5}$, which has a reduced amount of cellulose (Rui and Anderson, 2016), Young's moduli counterintuitively were predicted to increase in all three directions $\left(E_{1}, E_{2}\right.$, and $\left.E_{3}\right)$ (Table 3). Modeled shear moduli were lower in the longitudinal and circumferential directions than in the radial direction in cesa $3^{j e 5}$ stomata.

For FEMs of the $x x t 1 x x t 2$ genotype, which lacks xyloglucan (Cavalier et al., 2008), Young's moduli were predicted to be substantially lower than Col-0 moduli in the longitudinal, circumferential, and radial directions (Table 3). In addition, $E_{1}$ was larger than $E_{2}$ and $E_{3}$, a trend of anisotropic stiffness that is contrary to other genotypes. Combinations of these changes and additional constraints of neighboring cells might limit stomatal opening in $x x t 1 x x t 2$, as experimentally observed. In addition, the lower stiffness in $x x t 1 x x t 2$ guard cell walls suggests that a lack of xyloglucan significantly hampers the load-bearing mechanism of guard cell walls in normal deformations, which corroborates Park and Cosgrove (2015) finding. However, the smaller decreases in shear moduli than Young's moduli in $x x t 1 x x t 2$ suggest that the mechanism responsible for shear load bearing might involve xyloglucan and that it could be partially compensated for by other cell wall constituents, such as pectic polysaccharides, in the absence of xyloglucan.

For PGX1 OE, which has pectic polysaccharides with smaller molecular weight (Xiao et al., 2014), modeled changes in Young's modulus in the FEMs manifested differently in each direction. Compared to their counterparts in Col-0 controls, $E_{1}$ was lower, but $E_{2}$ and $E_{3}$ were higher in PGX1 OE guard cells. A lower $E_{1}$ value suggested that the decreased molecular weight of pectins might make it easier to stretch the guard cell in the longitudinal direction. Increases in $E_{2}$ and $E_{3}$ suggested a crucial role for pectins in the guard cell wall to achieve an appropriate level of stiffness in circumferential and radial directions (Rui et al., 2017). This suggests that a reduction in pectin molecular weight interferes with the load-bearing capability of the wall in the longitudinal direction, while the wall stiffens in the circumferential and radial directions. Increased pore opening in PGX1 OE stomata seemed to relate inversely to the longitudinal stiffness of the guard cell wall, as might be intuitively expected.

In $P G X 1$ OE FEMs, we also observed a much higher $G_{23}$ than that in Col-0 controls. This increase in $G_{23}$ suggested that in wild type stomata, large, flexible pectin molecules might serve as elastic buffers between layers of cellulose. In addition, the increased connectivity of networks of smaller pectic polysaccharides might inhibit wall deformation in the circumferential direction while moderately weakening mechanical stiffness in the longitudinal direction.

\section{Effects of Wall Composition on the Dynamic Geometry of Stomatal Complexes}

Whereas Col-0 stomata opened from 1.2 to $3.9 \mu \mathrm{m}$ in response to light treatment, cesa3 ${ }^{j e 5}$ stomata opened from 2.5 to $4.7 \mu \mathrm{m}$ (Table 1). Although cesa $3^{\text {jes }}$ stomatal pore widths were larger than Col-0 pore widths in both states (Table 1), the ratio of open to closed pore widths was smaller in cesa3 ${ }^{\text {jes }}$ (2:1) than that in Col-0 (3:1). This was reflected as an increase in the $E_{1}, E_{2}$, and $E_{3}$ values for FEMs of cesa3 ${ }^{j e 5}$ guard cell walls (Table 3). Smaller shear moduli of $c e s a 3^{j e 5}$ stomata in longitudinal and 
circumferential directions suggest a loss of resistance in the circumferential direction upon deformation in the longitudinal direction. Overall, considering that cesa $3^{j e 5}$ guard cells were predicted to have stiffer cell walls, increased pore opening of cesa $^{\text {je5 }}$ stomata was attributable more to altered initial stomatal geometry in comparison to Col-0 guard cells, rather than to reductions in wall stiffness in this cellulose-deficient mutant. Stomatal pore width was smaller in both open and closed $x x t 1 x x t 2$ stomata, and the ratio of open:closed stomatal pore width was larger than that of Col-0 stomata. Reflecting the observed stomatal opening and other geometric changes, the modeled stiffness of $x x t 1 x x t 2$ guard cell walls was substantially smaller than the stiffness of Col-0 walls (Table 3). The PGX1 $O E$ open:closed pore width ratio (6:1) was the largest among all genotypes, which was reflected in reductions in $E_{1}$ and $G_{12}$ (Table 3).

Counterintuitively, $E_{2}$ and $E_{3}$ did not directly correlate with changes in guard cell width during stomatal opening. For Col0 , guard cell width did not change upon opening $(p=0.85$, Mann-Whitney-Wilcox test). With lower $E_{2}$ and $E_{3}$ values, as in the case of $x x t 1 x x t 2$, guard cell width also remained the same upon opening ( $p=0.68$, Mann-Whitney-Wilcox test). However, when $E_{2}$ and $E_{3}$ were higher, as in case of cesa $3^{\text {je5 }}$ and PGX1 OE stomata, guard cell width still remained the same upon opening for cesa $3^{j e 5}$ ( $p=0.051$, Mann-Whitney-Wilcox test), but increased for PGX1 OE ( $p=0.00002$, Mann-WhitneyWilcox test), indicating radial expansion of guard cells in the latter genotype. The radial expansion of guard cells might reduce pore opening, similarly to the elliptical shape of guard cell cross sections proposed by (Cooke et al., 1976), and thus be detrimental to achieving a maximal stomatal pore area. It seems that the ratio between Young's moduli $\left(E_{1}, E_{2}\right.$, and $\left.E_{3}\right)$ and shear moduli involving the longitudinal direction $\left(G_{12}\right.$ and $\left.G_{13}\right)$ are more intimately related to guard cell expansion during stomatal opening.

\section{Stress and Strain Distribution in Guard Cells With Open Stomata}

Figure 8 shows typical results of modeled deformations of Col-0, cesa $3^{j e 5}, x x t 1 x x t 2$, and PGX1 OE stomata, respectively, upon $5 \mathrm{MPa}$ pressurization. In Col-0 FEMs, the amount of deformation was distributed evenly. For cesa $3^{j e 5}$ and PGX1 OE, wall deformation tended to be higher near the cell midsection, and junction areas showed smaller deformation, which is consistent with a limited change in stomatal complex length compared to a significant change in stomatal complex width (Rui and Anderson, 2016), and is consistent with polar stiffening during stomatal opening (Carter et al., 2017). On the other hand, $x x t 1 x x t 2$ FEMs show larger deformation near cell-cell junctions.

The concentration of deformations in specific regions might be predicted to hamper proper stomatal function after many rounds of stomatal movement, since these regions of the guard cell walls might be more subject to mechanical stress. However, the stress level of guard cell walls did not exhibit a similar spatial distribution (Figure 9). Noticeable stress concentration was observed near junctions and periclinal ridge regions. Dorsal or ventral regions did not show specific stress concentration, which might be advantageous for maintaining stomatal function across many rounds of opening and closure.

In our FEMs, additional loadings on junction and dorsal regions from neighboring cells were calculated in response to the imposed constraints on stomatal complex length and width determined by stomatal geometry measurements (Table 1). Loadings from neighboring cells on the dorsal regions of guard cells were similar for Col-0, cesa $3^{j e 5}$, and PGX1 OE, whereas $x x t 1$ $x x t 2$ FEMs required a much lower degree of loading (Table 4). Notably, constraints at the junction area needed to be much higher for Col-0 than for other genotypes, in which additional forces on junction area essentially vanished and it appeared that guard cells in these mutant genotypes lost mechanical support from neighboring cells (Table 4).

\section{DISCUSSION}

\section{Implications of Simplifying the Geometry of Stomatal Complexes}

A stomatal complex is a structure comprising a pair of guard cells that interact with neighboring subsidiary or pavement cells. Mechanically, a "structure" refers to a system of connected parts supporting imposed loads (Hibbeler, 2011). The following aspects influence the structure-load relationships that drive stomatal dynamics: (1) turgor pressure, (2) the shape and size of each guard cell, (3) guard cell wall thickness, (4) the geometry and configuration of connections between sister guard cells, (5) mechanical properties of the guard cell wall, and (6) support/constraint from neighboring cells. In modeling the opening and closing behavior of a stomatal complex, some of these aspects can be simplified. However, it is imperative to account for the implications of the assumptions that accompany each simplification in order to accurately interpret modeling results. Considering a stomatal complex as a mechanical structure, when the load imposed by turgor pressure, material model, modulus values, and thickness of the guard cell wall are set, there are two remaining important aspects to consider, namely connections between paired guard cells and interactions with neighboring cells. Here, we discuss implications from those aspects of simplified models of stomatal complexes and the benefits of using realistic models of stomatal complexes to overcome key limitations of the simplified models.

\section{Guard Cell Geometry}

In previous studies that model stomatal complexes, the overall shape of a guard cell pair or a stomatal pore has been simplified to be elliptic (DeMichele and Sharpe, 1973, 1974; Shoemaker and Srivastava, 1973; Cooke et al., 1976; Sharpe and Wu, 1978; Carter et al., 2017; Marom et al., 2017; Woolfenden et al., 2017). However, we observed significant asymmetry in many of the imaging-based FEMs we constructed, both at the subcellular scale, as evidenced by surface "bumpiness," and at the cellular scale, with guard cells bulging slightly on the opposite ends as their sister cells (Figure 8, Supplemental Figure 2). These observations call into question the assumption that stomatal 


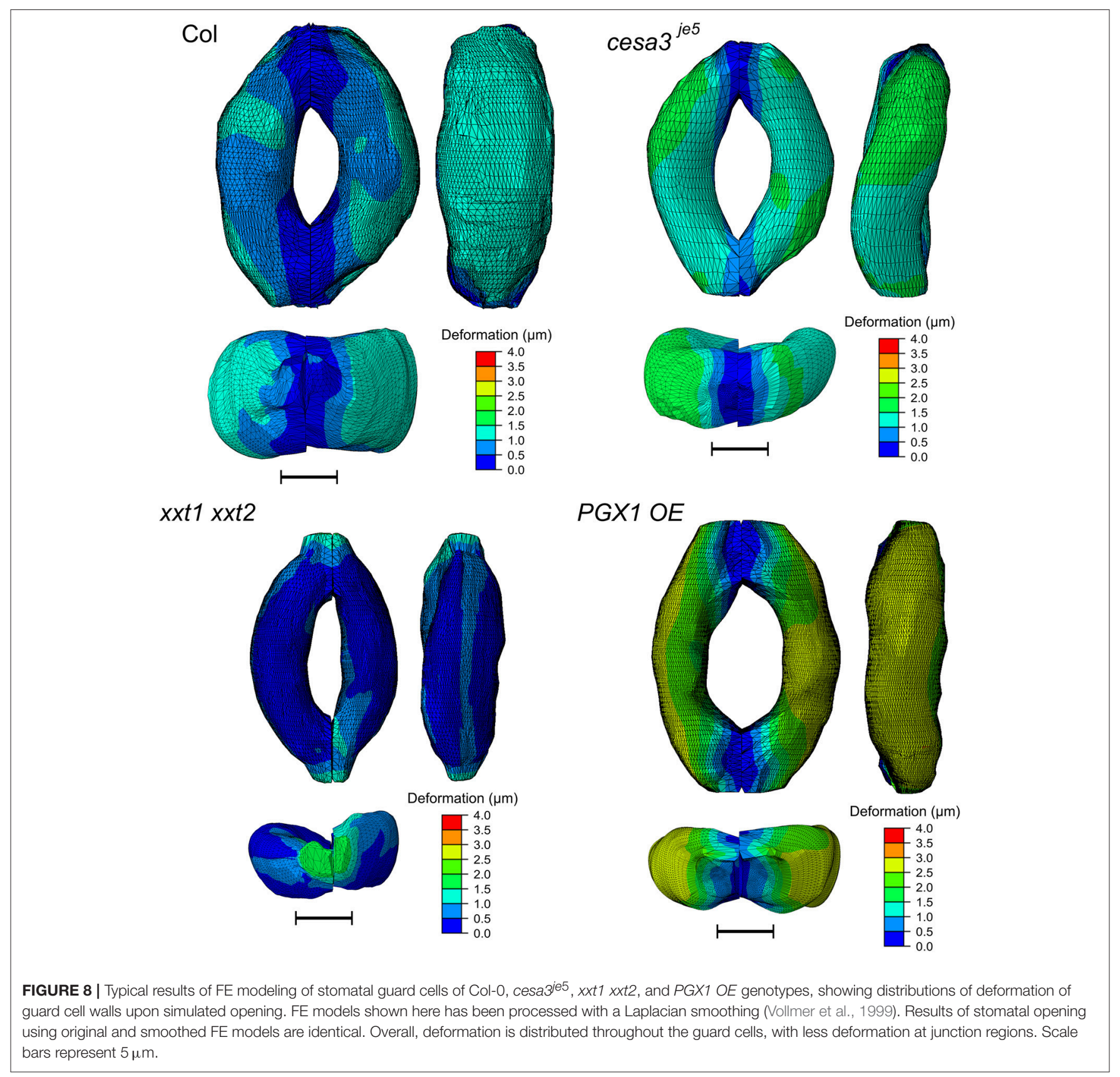

complexes are perfectly symmetrical, both longitudinally and transversely, when developing analytical and numerical models to represent stomatal dynamics (Cooke et al., 1976; Rui et al., 2016; Marom et al., 2017; Woolfenden et al., 2017).

Furthermore, assuming a simplified elliptical torus is a robust representation of a guard cell pair in a stomatal complex, simulation results of stomatal opening would be consistent under the same biomechanical conditions even when the geometry of a stomatal complex varies. From the comparison of two different stomatal complex geometries (Figure 3), it is clear that stomatal opening is sensitive to the overall guard cell shape.
Unfortunately, it is not straightforward to discern which geometric feature of a stomatal complex affects stomatal opening. For example, the shape of an open stomatal pore, which may be more relevant in stomatal functionality than pore width, is highly sensitive to the closed stomatal pore shape and the dorsal wall curvature of a guard cell. At the same time, stomatal junction length significantly affects stomatal pore enlargement in terms of the overall shape, maximum pore width, and pore area. Therefore, a simplified stomatal complex model aggregates such effects of simplification without a good way to validate their physical implications. By contrast, realistic stomatal complex models do not introduce assumptions about 

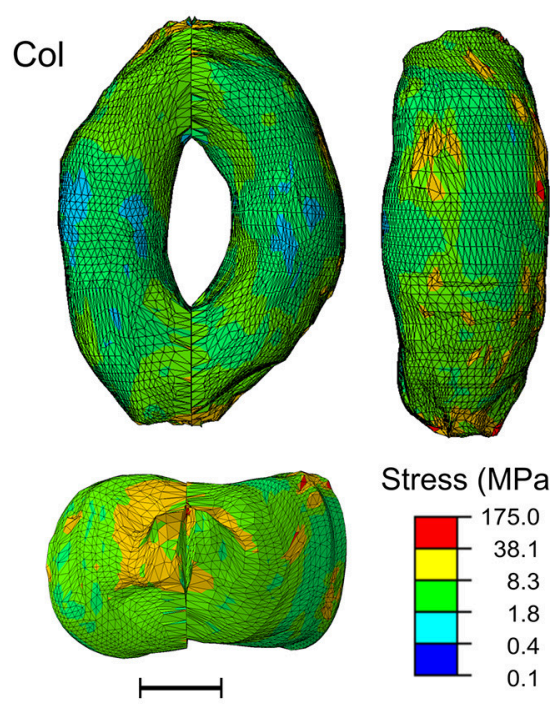

Stress (MPa)

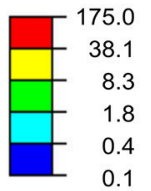

$x x t 1 x x t 2$
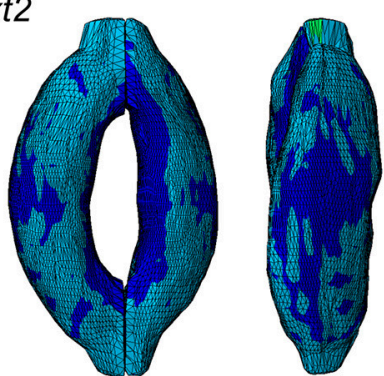

Stress (MPa)
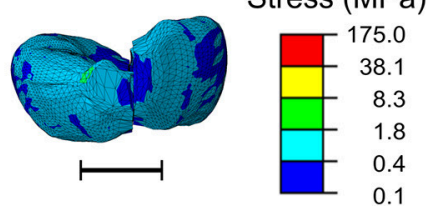
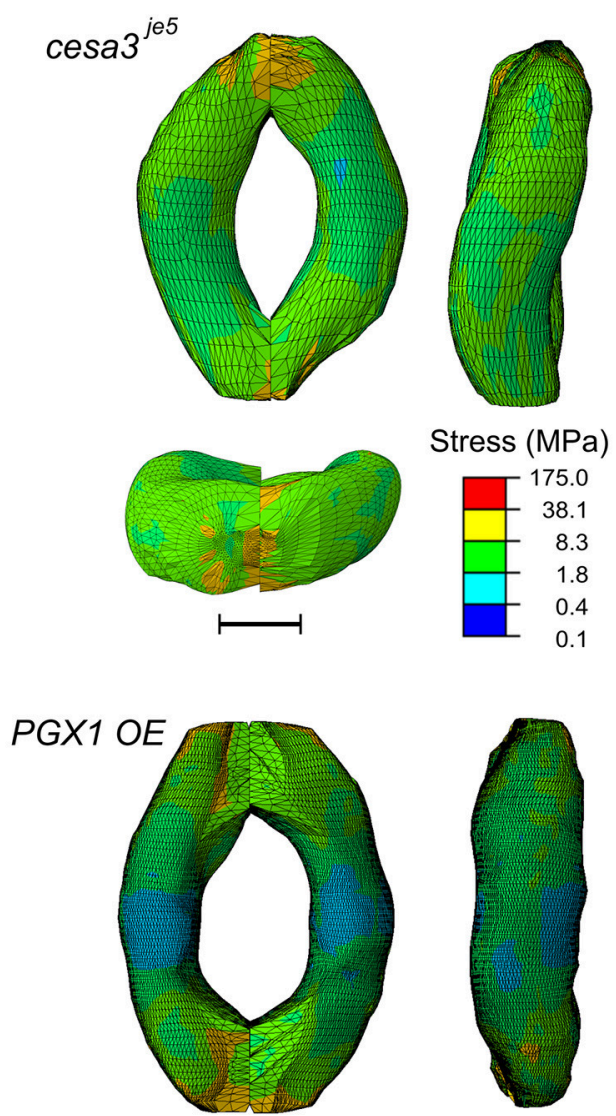

Stress (MPa)
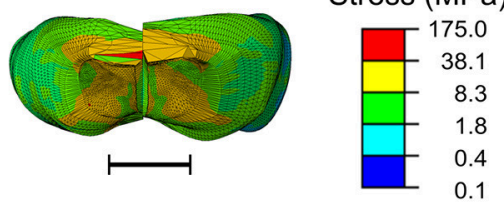

FIGURE 9 | Typical stress distributions in FE models of Col-0, cesa3 ${ }^{j e 5}, x x t 1$ xxt2, and PGX1 OE guard cells upon simulated opening. FE models shown here has been processed with a Laplacian smoothing (Vollmer et al., 1999). Results of stomatal opening using original and smoothed FE models are identical. Overall, stress concentration is observed near guard cell junctions and corners. Scale bars represent $5 \mu \mathrm{m}$.

TABLE 4 | Predicted additional loadings on stomatal guard cells at the dorsal side from neighboring cells and at junction area.

\begin{tabular}{lcc}
\hline Genotype & $\begin{array}{c}\text { Loading on stomatal } \\
\text { junction area (MPa) }\end{array}$ & $\begin{array}{c}\text { Loading on stomatal } \\
\text { dorsal area (MPa) }\end{array}$ \\
\hline Col-0 & 1.4 & 0.1 \\
cesa3 $^{j e 5}$ & -0.4 & 0.2 \\
$x x t 1$ xxt2 & -0.3 & 0.1 \\
PGX1 OE & -0.02 & 0.0001 \\
\hline
\end{tabular}

stomatal geometry, but instead reflect biological variations in stomatal geometry, including asymmetry between paired guard cells and any irregularity in stomatal pore shapes, thus avoiding any confounding effects of a simplified stomatal geometry.

\section{Interactions With Neighboring Cells}

A stomatal complex is connected to neighboring pavement cells. While a difference in turgor pressure between guard cells and pavement cells has not been quantitatively substantiated, it is clear that guard cells are supported by neighboring cells during stomatal opening and closing. Cooke et al. (1976) modeled this interaction as a component of boundary conditions. However, in recent modeling studies (Carter et al., 2017; Marom et al., 2017; Woolfenden et al., 2017), these interactions are not explicitly included.

As observed in Figure 4, pavement cell constraints on a stomatal complex have a significant effect on stomatal opening. The influence and importance of mechanical interaction between stomatal guard cells and pavement cells were originally investigated by DeMichele and Sharpe (1973), although the direction of mechanical advantage between guard cells and subsidiary cells are not always consistent. 
In conclusion, considering the existing complexity of mechanically modeling the guard cell wall and the number of geometric features of a stomatal complex, it is impractical to investigate and optimize the effect of each simplified aspect in isolation as part of a multifactorial exercise in model building. This is especially true when investigating stomatal complexes in different genotypes as their size and shape change simultaneously. Therefore, a clear advantage of using a realistic stomatal guard cell model traced from 3D microscopic images is that this approach constrains the geometry of the stomatal complex, simplifying the parameter space of the model, and makes this geometry realistic.

\section{The Anisotropic Mechanical Properties of Guard Cell Walls Reveal How Major Polysaccharides Contribute to Guard Cell Mechanics}

Our calculated Young's moduli and shear moduli highlight the highly anisotropic mechanical properties of guard cell walls. Higher stiffness values in circumferential or azimuthal $\left(E_{2}\right)$ and radial $\left(E_{3}\right)$ directions than in the longitudinal or polar direction $\left(E_{1}\right)$ corroborate previous results (Yi and Puri, 2012, 2014). In addition, Young's moduli ranging from 2 to $25 \mathrm{MPa}$ in the circumferential $\left(E_{2}\right)$ and radial $\left(E_{3}\right)$ directions and shear moduli of up to $750 \mathrm{MPa}$ in the longitudinal plane $\left(G_{23}\right)$ are much higher than stiffness values expected from non-covalent interactions, e.g., between cellulose and xyloglucan (Hayashi, 1989; McQueen-Mason and Cosgrove, 1994), cellulose and pectins (Zykwinska et al., 2005), or xyloglucan and pectins (Rizk et al., 2000; Brett et al., 2005; Cumming et al., 2005; Popper and Fry, 2008). These results suggest that load bearing by cellulose in the circumferential and radial directions in guard cell walls is a possible origin of the higher stiffness we modeled in the circumferential $\left(E_{2}\right)$ and radial $\left(E_{3}\right)$ directions. In the circumferential direction $\left(\mathrm{E}_{2}\right)$, an applied force is thought to be borne by the cellulose backbone. In the radial direction $\left(\mathrm{E}_{3}\right)$, an applied force is more likely to be borne by the compressive or tensile resistance of cellulose rather than the cell wall matrix.

Given the apparent dominance of cellulose in determining the anisotropic mechanical properties of the wall, the increased longitudinal stiffness $\left(E_{1}\right)$ we modeled in cesa $3^{\text {jes }}$ is counterintuitive. The deficiency of cellulose in guard cell walls results in overall guard cell enlargement, but not in enhanced radial expansibility (Rui and Anderson, 2016). Reflecting this result, in our FEMs of cellulose-deficient guard cell walls, stiffness increased greatly in the longitudinal direction, whereas it increased much less in the circumferential direction. However, shear modulus values, which constrain the radial expansion of guard cells, did not change as much (Table 2). These results suggest a direct correlation between cellulose content and wall stiffness in a direction perpendicular to CMF orientation $\left(E_{1}\right)$, which might be due to cellulose bundling and/or crosslinking by matrix polysaccharides. Compensatory changes in matrix polysaccharide abundance, interactions, and/or arrangements might arise in the absence of sufficient cellulose and cause this mechanical difference. Alternatively, a reduction in cellulose density might provide more contact sites at which matrix polymers can interact with CMFs, with these cellulose-matrix interactions perhaps being mechanically stronger than cellulosecellulose bundling interactions. Such increases in interactions between linker elements and CMFs should increase wall stiffness (Nili et al., 2015). This idea is further supported by the fact that shear moduli $\left(G_{12}, G_{23}\right.$, and $\left.G_{23}\right)$ in cesa3 ${ }^{j e 5}$ FEMs became isotropic. Together, these data suggest that reversible deformations of matrix polymers that interact with CMFs, in addition to CMF rearrangements (Rui and Anderson, 2016), occur during longitudinal deformation in guard cell walls.

Xyloglucan is thought to act as a tether or spacer between CMFs (Cosgrove, 2015; Park and Cosgrove, 2015), and because CMFs are highly oriented in guard cell walls (Fujita and Wasteneys, 2014; Rui and Anderson, 2016), the loss of xyloglucan in $x x t 1$ xxt2 mutants might have anisotropic effects on wall stiffness. This idea is supported by the observation that $x x t 1 x x t 2$ hypocotyls and open stomata display more anisotropic cellulose organization than wild type controls (Rui and Anderson, 2016; Xiao et al., 2016). The lower Young's moduli $\left(E_{1}, E_{2}\right.$, and $\left.E_{3}\right)$ and a reverse in the direction of anisotropy, with $E_{1}$ becoming larger than $E_{2}$ and $E_{3}$ that we modeled in $x x t 1 x x t 2$, suggest that a loss of cellulose-xyloglucan interconnections might not be compensated for by other matrix polymers such as pectins. The decreased wall stiffness modeled for this xyloglucan-deficient mutant corroborates a measured increase in plastic and elastic compliance in $x x t 1 x x t 2$ mutant petioles (Park and Cosgrove, 2012).

In PGX1 OE guard cells, which should have a reduction in HG molecular mass (Xiao et al., 2014; Phyo et al., 2017), the decrease in $E_{1}$ and increase in $E_{2}$ and $E_{3}$ we modeled might be explained by an increased number of pectin fragments that can interact more extensively with other wall components, enhancing the mechanical anisotropy of the guard cell wall. The decrease in $E_{1}$ in PGX1 OE guard cells agrees with previous data showing that promoting pectin de-methyl-esterification decreases cell wall stiffness as probed by AFM (Peaucelle et al., 2011, 2015). However, our findings of an increase in $E_{2}$ and $E_{3}$ in PGX1 OE compared to Col-0 do not agree with these previous studies, but do agree with other studies reporting stiffening effects of pectin de-methyl-esterification (Al-Qsous et al., 2004; Pelloux et al., 2007). In this case, pectin seems to play an important role in constraining the expansion of guard cell walls in circumferential vs. radial directions. Such a constraint should be an effective mechanism for anisotropic guard cell expansion during stomatal opening, over and above the radial-longitudinal constraints imposed by CMFs.

In addition, increased anisotropy upon pectin de-methylesterification, which can lead to either pectin crosslinking or degradation, is also observed by Peaucelle et al. (2015). A drastic increase in $G_{23}$ in PGX1 OE further suggests a contribution of HG to the anisotropic mechanics of guard cell walls. A higher $G_{23}$ in PGX1 OE cell walls also implies that strains in $E_{2}$ and $E_{3}$ are similar to one another during stomatal opening due to a higher resistance to change in angular deformation between the circumferential and radial directions than between other pairs of directions. Considering that shear modulus represents 
mechanical resistance to shape changes via interactions between layers, reducing $\mathrm{HG}$ molecular mass seems to tighten the mechanical coordination between circumferential and radial directions. In addition, decreased HG molecular mass resulted in decreased shear modulus $G_{12}$, which can be attributed to decreased inter-lamellar crosslinking in PGX1 OE guard cells. Overall, the decrease in cell wall stiffness probed by AFM (Peaucelle et al., 2011, 2015) suggests that $E_{1}$ plays a more crucial role than $E_{2}$ and $E_{3}$ in determining overall stiffness.

\section{Guard Cells Are Constrained by Neighboring Cells During Stomatal Opening}

To achieve agreement between our experimental observations and modeling results, we considered mechanical constraints from neighboring cells. This concept differs from scenarios invoking mechanical advantages between pavement cells and guard cells (Meidner and Mansfield, 1968; Aylor et al., 1973; DeMichele and Sharpe, 1973; Edwards et al., 1976; Zeiger et al., 1987; Niklas, 1992; Franks et al., 1998). We found that physical constraints from neighboring cells limit deformations of guard cell width and stomatal complex length when stomata open. In other words, this observation suggests that increased turgor alone cannot induce the experimentally observed stomatal opening with almost no radial expansion of guard cells or changes in stomatal complex length (Table 1 and Figure 7).

We and others (Rui and Anderson, 2016; Woolfenden et al., 2017) have observed very little or no change in guard cell width upon stomatal opening. In our FEMs, none of the physically possible combinations of wall mechanical properties resulted in as small a change in guard cell width as in the experimental measurements (Figure 7), with the exception of $x x t 1 x x t 2$. This discrepancy between experimental measurements and modeling results strongly suggests that there may be specific mechanical properties that constrain the deformation of the ventral, or pore, side of the guard cell. One possible origin of this constraint is the enhanced thickening of the inner and outer periclinal walls in proximity to the ventral plane (Supplemental Figure 1), which would allow for stretching but not significant lateral displacement of the ventral wall itself with respect to the guard cell radius.

For stomatal complex length, there are marginal changes in Col-0 upon stomatal opening, whereas it actually decreased in cesa $^{j e 5}, x x t 1 x x t 2$, and PGX1 OE plants. Such reductions can only be achieved by applying additional external forces, because higher mechanical stiffness can only achieve smaller deformation but not a deformation in the opposite direction to the imposed turgor.

An extracellular load applied to the junction area during stomatal opening would prevent the elongation of the whole stomatal complex, which is consistent with a recently proposed polar fixing model (Carter et al., 2017). Combining FEM results of higher stress near stomatal junctions with the additional mechanical interaction with pavement cells in the same region, an enrichment of pectic polysaccharides near guard cell junctions (Carter et al., 2017; Rui et al., 2017) can be hypothesized to contribute to the enhanced mechanical stiffness in this region. On the other hand, a higher level of stress near periclinal ridge regions seems to be linked to thicker guard cell walls in this region. However, an additional constraint at the junction was not required for the mutant genotypes we analyzed, especially in the case of $x x t 1 x x t 2$, suggesting that some cell wall defects might lead to mechanical uncoupling of stomatal complexes from their epidermal neighbors.

\section{Future Work}

Even though modeled geometries of guard cells of different genotypes closely matched measurements from $3 \mathrm{D}$ microscopic images of actual stomata, our current FEMs could be further improved by higher-resolution microscopy and automated landmarking. Automated landmarking to trace the innermost and/or outermost layers of guard cell walls in 3D will allow FE modeling to incorporate guard cell wall properties such as varying thickness around the periphery of each guard cell (Zhao and Sack, 1999) and to further investigate comprehensive stomatal geometries such as stomatal pore area. Expansion of the automated landmarking approach will also allow neighboring cells to be modeled together so that their interaction with guard cells can be simulated. Furthermore, a multiscale computational model that describes individual components in the walls of guard cells and their molecular interactions with high spatial precision could be used to further examine how plants regulate guard cell walls to achieve repetitive and elastic deformations during stomatal dynamics.

\section{ACCESSION NUMBERS}

Sequence data from this article can be found in the Arabidopsis Genome Initiative or GenBank/EMBL databases under the following accession numbers: CESA3 (At5g05170), XXT1 (At3g62720), XXT2 (At4g02500), and PGX1 (At3g26610).

\section{AUTHOR CONTRIBUTIONS}

YR and CA designed experiments. YR performed experiments. $\mathrm{BK}$ and JW built computational analysis pipelines for imaging data. HY and VP developed FE models. HY, VP, YR, BK, JW, and CA analyzed results and HY, YR, BK, VP, JW, and CA wrote the manuscript.

\section{ACKNOWLEDGMENTS}

Research supplies were purchased with support from a Huck Dissertation Research Award to YR. This work was supported by the National Science Foundation under Grant MCB-1616316 awarded to CA, JW, and VP.

\section{SUPPLEMENTARY MATERIAL}

The Supplementary Material for this article can be found online at: https://www.frontiersin.org/articles/10.3389/fpls.2018. 01566/full\#supplementary-material 


\section{REFERENCES}

Al-Qsous, S., Carpentier, E., Klein-Eude, D., Burel, C., Mareck, A., Dauchel, H., et al. (2004). Identification and isolation of a pectin methylesterase isoform that could be involved in flax cell wall stiffening. Planta 219, 369-378. doi: $10.1007 / \mathrm{s} 00425-004-1246-1$

Amsbury, S., Hunt, L., Elhaddad, N., Baillie, A., Lundgren, M., Verhertbruggen, Y., et al. (2016). Stomatal function requires pectin De-methyl-esterification of the guard cell wall. Curr. Biol. 26, 2899-2906. doi: 10.1016/j.cub.2016.08.021

Aylor, D. E., Parlange, J.-Y., and Krikorian, A. D. (1973). Stomatal mechanics. Am. J. Bot. 60:163-171. doi: 10.1002/j.1537-2197.1973.tb10213.x

Bathe, K. J. (1996). Finite Element Procedures. Englewood Cliffs, NJ: Prentice Hall Inc.

Brett, C. T., Baydoun, E.-H., and Abdel-Massih, R. M. (2005). Pectin - xyloglucan linkages in type I primary cell walls of plants. Plant Biosyst. Int. J. Deal. Asp. Plant Biol. 139, 54-59. doi: 10.1080/11263500500056732

Broyden, C. G. (1965). A class of methods for solving nonlinear simultaneous equations. Math. Comput. 19, 577-593. doi: 10.1090/S0025-5718-1965-0198670-6

Carter, R., Woolfenden, H., Baillie, A., Amsbury, S., Carroll, S., Healicon, E., et al. (2017). Stomatal opening involves polar, not radial, stiffening of guard cells. Curr. Biol. 27, 2974-2983.e2. doi: 10.1016/j.cub.2017.08.006

Cavalier, D. M., Lerouxel, O., Neumetzler, L., Yamauchi, K., Reinecke, A., Freshour, G., et al. (2008). Disrupting two Arabidopsis thaliana xylosyltransferase genes results in plants deficient in xyloglucan, a major primary cell wall component. Plant Cell 20, 1519-1537. doi: 10.1105/tpc.108.059873

Cintrón, M. S., Johnson, G., and French, A. (2011). Young's modulus calculations for cellulose I $\beta$ by MM3 and quantum mechanics. Cellulose 18, 505-516. doi: 10.1007/s10570-011-9507-1

Cooke, J. R., DeBaerdemaeker, J. G., Rand, R. H., and Mang, H. A. (1976). A finite element shell analysis of guard cell deformations. Trans. ASAE 19:1107.

Cosgrove, D. J. (2005). Growth of the plant cell wall. Nat. Rev. Mol. Cell Biol. 6, 850-861. doi: 10.1038/nrm1746

Cosgrove, D. J. (2015). Plant cell wall extensibility: connecting plant cell growth with cell wall structure, mechanics, and the action of wall-modifying enzymes. J. Exp. Bot. 67, 463-476. doi: 10.1093/jxb/erv511

Cumming, C. M., Rizkallah, H. D., McKendrick, K. A., Abdel-Massih, R. M., Baydoun, E. A., and Brett, C. T. (2005). Biosynthesis and cell-wall deposition of a pectin-xyloglucan complex in pea. Planta 222, 546-555. doi: 10.1007/s00425-005-1560-2

Dassault Systèmes (2016). Abaqus. Providence, RI: Dassault Systèmes.

DeMichele, D. W., and Sharpe, P. J. (1973). An analysis of the mechanics of guard cell motion. J. Theor. Biol. 41, 77-96. doi: 10.1016/0022-5193(73)90190-2

DeMichele, D. W., and Sharpe, P. J. H. (1974). A parametric analysis of the anatomy and physiology of the stomata. Agric. Meteorol. 14, 229-241. doi: 10.1016/0002-1571(74)90022-3

Desprez, T., Juraniec, M., Crowell, E. F., Jouy, H., Pochylova, Z., Parcy, F., et al. (2007). Organization of cellulose synthase complexes involved in primary cell wall synthesis in Arabidopsis thaliana. Proc. Natl. Acad. Sci. U.S.A. 104, 15572-15577. doi: 10.1073/pnas.0706569104

Dierckx, P. (1982). Algorithms for smoothing data with periodic and parametric splines. Comput. Graph. Image Process. 20, 171-184. doi: 10.1016/0146-664X(82)90043-0

Dri, F. L, Hector, L. G, Jr., Moon, R. J., and Zavattieri, P. D. (2013). Anisotropy of the elastic properties of crystalline cellulose I $\beta$ from first principles density functional theory with Van der Waals interactions. Cellulose 20, 2703-2718. doi: 10.1007/s10570-013-0071-8

Edwards, M., Meidner, H., and Sheriff, D. W. (1976). Direct Measurements of turgor pressure potentials of guard cells II. the mechanical advantage of subsidiary cells, the spannunqsphase, and the optimum leaf water deficit. J. Exp. Bot. 27, 163-171. doi: 10.1093/jxb/27.1.163

Forouzesh, E., Goel, A., Mackenzie, S. A., and Turner, J. A. (2013). In vivo extraction of Arabidopsis cell turgor pressure using nanoindentation in conjunction with finite element modeling. Plant J. 73, 509-520. doi: $10.1111 /$ tpj. 12042

Franks, P. J., Beerling, D. J., and Berner, R. A. (2009). Maximum leaf conductance driven by $\mathrm{CO} 2$ effects on stomatal size and density over geologic time. Proc. Natl. Acad. Sci. U.S.A. 106, 10343-10347. doi: 10.1073/pnas.0904209106

Franks, P. J., Buckley, T. N., Shope, J. C., and Mott, K. A. (2001). Guard cell volume and pressure measured concurrently by confocal microscopy and the cell pressure probe. Plant Physiol. 125, 1577-1584. doi: 10.1104/pp.125.4.1577
Franks, P. J., Cowan, I. R., and Farquhar, G. D. (1998). A study of stomatal mechanics using the cell pressure probe. Plant Cell Environ. 21, 94-100. doi: 10.1046/j.1365-3040.1998.00248.x

Franks, P. J., and Farquhar, G. D. (2001). The effect of exogenous abscisic acid on stomatal development, stomatal mechanics, and leaf gas exchange in Tradescantia virginiana. Plant Physiol. 125, 935-942. doi: 10.1104/pp.125. 2.935

Franks, P. J., and Farquhar, G. D. (2007). The Mechanical diversity of stomata and its significance in gas-exchange control. Plant Physiol. 143, 78-87. doi: 10.1104/pp.106.089367

Fujita, M., and Wasteneys, G. O. (2014). A survey of cellulose microfibril patterns in dividing, expanding, and differentiating cells of Arabidopsis thaliana. Protoplasma 251, 687-698. doi: 10.1007/s00709-013-0571-2

Geuzaine, C., and Remacle, J.-F. (2009). Gmsh: A 3-D finite element mesh generator with built-in pre-and post-processing facilities. Int. J. Numer. Methods Eng. 79, 1309-1331. doi: 10.1002/nme.2579

Hammer, Ø., Harper, D. A. T., and Ryan, P. D. (2008). PAST-palaeontological statistics, ver. 1.89. Paleontol. Mus. Univ. Oslo NoruegaTambién Dispon. En Linea Httpfolk Uio Noohammerpastindex Html. Available online at: https:// www.researchgate.net/profile/Paul_Ryan11/publication/228393561_PASTPalaeontological_statistics_ver_189/links/02bfe5135d45cd6b3b000000.pdf (Accessed October 12, 2017).

Hayashi, T. (1989). Xyloglucans in the primary cell wall. Annu. Rev. Plant Physiol. Plant Mol. Biol. 40, 139-168. doi: 10.1146/annurev.pp.40.060189.001035

Hibbeler, R. C. (2011). Structural Analysis, 8th Edn. Boston, MA: Prentice Hall Inc. Jones, E., Oliphant, T., Peterson, P., and others (2001). SciPy: Open Source Scientific Tools for Python. Available online at: http://www.scipy.org/

Jones, L., Milne, J. L., Ashford, D., McCann, M. C., and McQueenMason, S. J. (2005). A conserved functional role of pectic polymers in stomatal guard cells from a range of plant species. Planta 221, 255-264. doi: 10.1007/s00425-004-1432-1

Jones, L., Milne, J. L., Ashford, D., and McQueen-Mason, S. J. (2003). Cell wall arabinan is essential for guard cell function. Proc. Natl. Acad. Sci. U.S.A. 100, 11783-11788. doi: 10.1073/pnas.1832434100

Kass, M., Witkin, A., and Terzopoulos, D. (1988). Snakes: active contour models. Int. J. Comput. Vis. 1, 321-331. doi: 10.1007/BF00133570

Kim, K., Yi, H., Zamil, M. S., Haque, M. A., and Puri, V. M. (2015). Multiscale stress-strain characterization of onion outer epidermal tissue in wet and dry states. Am. J. Bot. 102, 12-20. doi: 10.3732/ajb.1400273

Kim, T.-H., Böhmer, M., Hu, H., Nishimura, N., and Schroeder, J. I. (2010). Guard cell signal transduction network: advances in understanding abscisic acid, $\mathrm{CO}_{2}$, and $\mathrm{Ca}^{2+}$ Signaling. Annu. Rev. Plant Biol. 61, 561-591. doi: 10.1146/annurev-arplant-042809-112226

Marom, Z., Shtein, I., and Bar-On, B. (2017). Stomatal opening: the role of cellwall mechanical anisotropy and its analytical relations to the bio-composite characteristics. Front. Plant Sci. 8:2061. doi: 10.3389/fpls.2017.02061

McQueen-Mason, S., and Cosgrove, D. J. (1994). Disruption of hydrogen bonding between plant cell wall polymers by proteins that induce wall extension. Proc. Natl. Acad. Sci. U.S.A. 91, 6574-6578. doi: 10.1073/pnas.91.14.6574

Meckel, T., Gall, L., Semrau, S., Homann, U., and Thiel, G. (2007). Guard cells elongate: relationship of volume and surface area during stomatal movement. Biophys. J. 92, 1072-1080. doi: 10.1529/biophysj.106.092734

Meidner, H., and Mansfield, T. A. (1968). Physiology of Stomata. London: McGrawHill.

Milani, P., Gholamirad, M., Traas, J., Arnéodo, A., Boudaoud, A., Argoul, F., et al. (2011). In vivo analysis of local wall stiffness at the shoot apical meristem in Arabidopsis using atomic force microscopy. Plant J. 67, 1116-1123. doi: 10.1111/j.1365-313X.2011.04649.x

Motulsky, H. J., and Brown, R. E. (2006). Detecting outliers when fitting data with nonlinear regression - a new method based on robust nonlinear regression and the false discovery rate. BMC Bioinformatics 7:123. doi: 10.1186/1471-2105-7-123

Niklas, K. J. (1992). Plant Biomechanics; An Engineering Approach to Plant Form and Function. Chicago; London: University of Chicago Press

Nili, A., Yi, H., Crespi, V. H., and Puri, V. M. (2015). Examination of biological hotspot hypothesis of primary cell wall using a computational cell wall network model. Cellulose 22, 1027-1038. doi: 10.1007/s10570-015-0568-4

Nishiyama, Y., Johnson, G. P., French, A. D., Forsyth, V. T., and Langan, P. (2008). Neutron crystallography, molecular dynamics, and quantum mechanics studies of the nature of hydrogen bonding in cellulose I $\beta$. Biomacromolecules 9 , 3133-3140. doi: 10.1021/bm800726v 
Park, Y. B., and Cosgrove, D. J. (2012). Changes in cell wall biomechanical properties in the Xyloglucan-Deficient xxt1/xxt2 Mutant of Arabidopsis. Plant Physiol. 158, 465-475. doi: 10.1104/pp.111.189779

Park, Y. B., and Cosgrove, D. J. (2015). Xyloglucan and its interactions with other components of the growing cell wall. Plant Cell Physiol. 56:180-194. doi: $10.1093 /$ pcp/pcu204

Peaucelle, A., Braybrook, S. A., Le Guillou, L., Bron, E., Kuhlemeier, C., and Höfte, H. (2011). Pectin-Induced changes in cell wall mechanics underlie organ initiation in arabidopsis. Curr. Biol. 21, 1720-1726. doi: 10.1016/j.cub.2011.08.057

Peaucelle, A., Wightman, R., and Höfte, H. (2015). The control of growth symmetry breaking in the Arabidopsis hypocotyl. Curr. Biol. 25, 1746-1752. doi: $10.1016 /$ j.cub.2015.05.022

Pelloux, J., Rustérucci, C., and Mellerowicz, E. J. (2007). New insights into pectin methylesterase structure and function. Trends Plant Sci. 12, 267-277. doi: 10.1016/j.tplants.2007.04.001

Peng, H., Ruan, Z., Long, F., Simpson, J. H., and Myers, E. W. (2010). V3D enables real-time $3 \mathrm{D}$ visualization and quantitative analysis of large-scale biological image data sets. Nat. Biotechnol. 28, 348-353. doi: 10.1038/nbt.1612

Phyo, P., Wang, T., Xiao, C., Anderson, C. T., and Hong, M. (2017). Effects of pectin molecular weight changes on the structure, dynamics, and polysaccharide interactions of primary cell walls of Arabidopsis thaliana: insights from solid-state NMR. Biomacromolecules 18, 2937-2950. doi: 10.1021/acs.biomac.7b00888

Pillitteri, L. J., and Torii, K. U. (2012). Mechanisms of stomatal development. Аnnu. Rev. Plant Biol. 63, 591-614. doi: 10.1146/annurev-arplant-042811-105451

Popper, Z. A., and Fry, S. C. (2008). Xyloglucan-pectin linkages are formed intraprotoplasmically, contribute to wall-assembly, and remain stable in the cell wall. Planta 227, 781-794. doi: 10.1007/s00425-007-0656-2

Quesada Cabrera, R., Meersman, F., McMillan, P. F., and Dmitriev, V. (2011). Nanomechanical and structural properties of native cellulose under compressive stress. Biomacromolecules 12, 2178-2183. doi: $10.1021 / \mathrm{bm} 200253 \mathrm{~h}$

R Core Team (2016). R: A Language and Environment for Statistical Computing. Vienna, Austria: R Foundation for Statistical Computing Available online at: https://www.R-project.org/

Rizk, S. E., Abdel-Massih, R. M., Baydoun, E. A., and Brett, C. T. (2000). Proteinand $\mathrm{pH}$-dependent binding of nascent pectin and glucuronoarabinoxylan to xyloglucan in pea. Planta 211, 423-429. doi: 10.1007/s004250000303

Rui, Y., and Anderson, C. T. (2016). Functional analysis of cellulose and xyloglucan in the walls of stomatal guard cells of Arabidopsis thaliana. Plant Physiol. 170, 1398-1419. doi: 10.1104/pp.15.01066

Rui, Y., Xiao, C., Yi, H., Kandemir, B., Wang, J. Z., Puri, V. M., et al. (2017). Polygalacturonase involved in expansion 3 functions in seedling development, rosette growth, and stomatal dynamics in Arabidopsis thaliana. Plant Cell 29, 2413-2432. doi: 10.1105/tpc.17.00568

Rui, Y., Yi, H., Kandemir, B., Wang, J. Z., Puri, V. M., and Anderson, C. T. (2016). Integrating cell biology, image analysis, and computational mechanical modeling to analyze the contributions of cellulose and xyloglucan to stomatal function. Plant Signal. Behav. 11:e1183086. doi: $10.1080 / 15592324.2016 .1183086$

Savitzky, A., and Golay, M. J. E. (1964). Smoothing and differentiation of data by simplified least squares procedures. Anal. Chem. 36, 1627-1639. doi: 10.1021/ac60214a047

Sharpe, P. J. H., and Wu, H.-I. (1978). Stomatal mechanics: volume changes during opening. Plant Cell Environ. 1, 259-268. doi: 10.1111/j.1365-3040.1978.tb02038.x

Shoemaker, E. M., and Srivastava, L. M. (1973). The mechanics of stomatal opening in corn (Zea mays L.) leaves. J Theor Biol. 42, 219-225.

Vanstreels, E., Alamar, M. C., Verlinden, B. E., Enninghorst, A., Loodts, J. K. A., Tijskens, E., et al. (2005). Micromechanical behaviour of onion epidermal tissue. Postharvest Biol. Technol. 37, 163-173. doi: 10.1016/j.postharvbio.2005.04.004

Vollmer, J., Mencl, R., and Müller, H. (1999). improved laplacian smoothing of noisy surface meshes. Comp. Graph. Forum 18, 131-138. doi: 10.1111/1467-8659.00334

von Caemmerer, S., and Farquhar, G. D. (1981). Some relationships between the biochemistry of photosynthesis and the gas exchange of leaves. Planta 153, 376-387. doi: 10.1007/BF00384257
Wei, C., and Lintilhac, P. M. (2007). Loss of stability: a new look at the physics of cell wall behavior during plant cell growth. Plant Physiol. 145, 763-772. doi: $10.1104 /$ pp.107.101964

Wickham, H. (2009). ggplot2: Elegant Graphics for Data Analysis. New York, NY: Springer-Verlag Available online at: http://ggplot2.org. doi: 10.1007/978-0-387-98141-3

Woolfenden, H. C., Bourdais, G., Kopischke, M., Miedes, E., Molina, A., Robatzek, S., et al. (2017). A computational approach for inferring the cell wall properties that govern guard cell dynamics. Plant J. 92, 5-18. doi: 10.1111/tpj. 13640

Wu, H.-I., and Sharpe, P. J. H. (1979). Stomatal mechanics II*: material properties of guard cell walls. Plant Cell Environ. 2, 235-244. doi: 10.1111/j.1365-3040.1979.tb00075.x

Wu, X., Moon, R. J., and Martini, A. (2013). Crystalline cellulose elastic modulus predicted by atomistic models of uniform deformation and nanoscale indentation. Cellulose 20, 43-55. doi: 10.1007/s10570-0129823-0

Xiao, C., Somerville, C., and Anderson, C. T. (2014). Polygalacturonase involved in expansion 1 functions in cell elongation and flower development in arabidopsis. Plant Cell 26, 1018-1035. doi: 10.1105/tpc.114.123968

Xiao, C., Zhang, T., Zheng, Y., Cosgrove, D. J., and Anderson, C. T. (2016). xyloglucan deficiency disrupts microtubule stability and cellulose biosynthesis in arabidopsis, altering cell growth and morphogenesis. Plant Physiol. 170, 234-249. doi: 10.1104/pp.15.01395

Yi, H., and Puri, V. M. (2012). Architecture-based multiscale computational modeling of plant cell wall mechanics to examine the hydrogen-bonding hypothesis of the cell wall network structure model. Plant Physiol. 160, 1281-1292. doi: 10.1104/pp.112.201228

Yi, H., and Puri, V. M. (2014). Contributions of the mechanical properties of major structural polysaccharides to the stiffness of a cell wall network model. Am. J. Bot. 101, 244-254. doi: 10.3732/ajb.1300315

Zamil, M. S., Yi, H., Haque, M. A., and Puri, V. M. (2013). Characterizing microscale biological samples under tensile loading: stress-strain behavior of cell wall fragment of onion outer epidermis. Am. J. Bot. 100, 1105-1115. doi: 10.3732/ajb.1200649

Zamil, M. S., Yi, H., and Puri, V. M. (2014). Mechanical characterization of outer epidermal middle lamella of onion under tensile loading. Am. J. Bot. 101, 778-787. doi: 10.3732/ajb.1300416

Zamil, M. S., Yi, H., and Puri, V. M. (2015). The mechanical properties of plant cell walls soft material at the subcellular scale: the implications of water and of the intercellular boundaries. J. Mater. Sci. 50, 6608-6623. doi: 10.1007/s10853-015-9204-9

Zeiger, E., Farquhar, G., D., and Cowan, I. R. (1987). Stomatal Function. Stanford, CA: Stanford University Press.

Zhang, T., Vavylonis, D., Durachko, D. M., and Cosgrove, D. J. (2017). Nanoscale movements of cellulose microfibrils in primary cell walls. Nat. Plants 3:17056. doi: $10.1038 /$ nplants.2017.56

Zhao, L., and Sack, F. D. (1999). Ultrastructure of stomatal development in Arabidopsis (Brassicaceae) leaves. Am. J. Bot. 86, 929-939. doi: $10.2307 / 2656609$

Zienkiewicz, O. C., Taylor, R. L., and Fox, D. (2014). "Chapter 1 - General Problems in Solid Mechanics and Nonlinearity," in The Finite Element Method for Solid and Structural Mechanics (Seventh Edition) (Oxford: ButterworthHeinemann), 1-20. Available online at: http://www.sciencedirect.com/science/ article/pii/B9781856176347000016 (Accessed May 24, 2016).

Zykwinska, A. W., Ralet, M. C., Garnier, C. D., and Thibault, J. F. (2005). Evidence for in vitro binding of pectin side chains to cellulose. Plant Physiol. 139, 397-407. doi: 10.1104/pp.105.065912

Conflict of Interest Statement: The authors declare that the research was conducted in the absence of any commercial or financial relationships that could be construed as a potential conflict of interest.

Copyright $\odot 2018$ Yi, Rui, Kandemir, Wang, Anderson and Puri. This is an openaccess article distributed under the terms of the Creative Commons Attribution License (CC BY). The use, distribution or reproduction in other forums is permitted, provided the original author(s) and the copyright owner $(s)$ are credited and that the original publication in this journal is cited, in accordance with accepted academic practice. No use, distribution or reproduction is permitted which does not comply with these terms. 